Article

\title{
Synthesis and DPPH Radical Scavenging Activity of Prenylated Phenol Derivatives
}

\author{
Mauricio Osorio ${ }^{1, *}$, Jacqueline Aravena ${ }^{1}$, Alejandra Vergara ${ }^{1}$, Lautaro Taborga ${ }^{1}$, \\ Evelyn Baeza ${ }^{1}$, Karen Catalán ${ }^{1}$, Cesar González ${ }^{1}$, Marcela Carvajal ${ }^{1}$, Héctor Carrasco ${ }^{2}$ and \\ Luis Espinoza 1
}

1 Departamento de Química, Universidad Técnica Federico Santa María, Av. España $\mathrm{N}^{\circ} 1680$, Valparaíso, 2390123, Chile

2 Departamento de Ciencias Químicas, Universidad Andrés Bello, Campus Viña del Mar, Los Fresnos N 52, Viña del Mar, 2561156, Chile

* Author to whom correspondence should be addressed; E-Mail: mauricio.osorio@usm.cl; Tel.: +56-32-265-4226.

Received: 2 December 2011; in revised form: 27 December 2011 / Accepted: 4 January 2012 / Published: 6 January 2012

\begin{abstract}
The synthesis of twenty six prenylated phenols derivatives is reported. These compounds were obtained under mild conditions via Electrophilic Aromatic Substitution $(E A S)$ coupling reactions between phenol derivatives containing electron-donor subtituents and 3-methyl-2-buten-1-ol using $\mathrm{BF}_{3} \cdot \mathrm{OEt}_{2}$. Dialkylations were also produced with this method. The formation of a chroman ring by intramolecular cyclization between a $\mathrm{sp}^{2}$ carbon from the prenyl group with the hydroxyl substituent in the ortho position occurred with some phenols. All the synthesized compounds were evaluated as antioxidants according to a DPPH radical scavenging activity assay. $\mathrm{IC}_{50}$ values of five synthesized compounds indicated they were as good antioxidants as Trolox ${ }^{\mathrm{TM}}$.
\end{abstract}

Keywords: prenylated phenols; electrophilic aromatic substitution; radical scavenging activity

\section{Introduction}

Prenylated phenols constitute an interesting group of marine natural products, for which a wide variety of biological activities have been described, including anti-inflammatory [1,2], antifungal [3], 
anti-HIV [4], anti-Alzheimer activity [5] and most frequently, antineoplastic properties [6,7]. ortho-Prenylated phenols play an important role in mediating many biological processes. For instance, prenylated ubiquinones are essential in cellular respiration [8]. Clearly, such an important structural motif needs a general strategy for its preparation, particularly for systems in which other aromatic hydroxyl residues are differentiated, as is often the case with therapeutic natural products containing this pharmacophore.

As a part of our ongoing interest in developing new and efficient antitumour agents, we recently reported the synthesis of two new hemisynthetic diterpenylhydroquinones from natural ent-labdanes by coupling between an arene nucleus and an allylic alcohol, which showed important activity in the inhibition of the growth of cancerigenous cells $[9,10]$. This kind of molecules are structural analogs of terpenylquinones and terpenylhydroquinones which are characteristic marine metabolites frequently isolated from alga and/or sponge [11,12].

Terpenylphenols are isolated from natural sources in very low yield, and for that reason during the last few decades, considerable research effort has been focused on obtaining these compounds by synthesis. The most recurrent strategies used for synthesizing these compounds involve, as a first step, the separate preparation of the appropriate terpenyl fragments and aromatic nucleus. The crucial step is the attachment of the aromatic synthon to the terpenyl skeleton [13]. There are many publications that report different methods for accomplishing these coupling reactions in the synthesis of prenylphenols, but the most interesting method for us is the Electrophilic Aromatic Substitution (EAS) reaction between a phenol and the corresponding prenol by using $\mathrm{BF}_{3} \cdot \mathrm{OEt}_{2}$ because of its simplicity and mild reaction conditions $[8,14]$.

Endogenous free radicals generated during body metabolism play an important role in the human health by causing several diseases including cancer, hypertension, heart attack and diabetes. Oxidation of low-density lipoprotein (LDL) is thought to play a central role in atherosclerosis. Reactive oxygen and nitrogen species as singlet oxygen, superoxide radicals, peroxyl radicals, hydroxyl radicals, and peroxynitrite can react with critical cellular components such as DNA, lipids, and proteins leading to tissue injury and contributing to chronic diseases. In recent years much attention has been focused on the use of natural dietary antioxidants as an effective protection against diseases related to oxidative processes [15-17]. A series of prenylated phenols derivatives were synthesized and their antioxidant activities (DPPH radical scavenging activity) were evaluated.

\section{Results and Discussion}

\subsection{Synthesis}

The synthesis of prenylated phenols was carried out in one step via the $E A S$ mechanism as shown in Scheme 1. The reaction of different phenols $\mathbf{1}-\mathbf{6}$ with prenol in the presence of $\mathrm{BF}_{3}$ etherate in a $1: 1$ mixture of diethyl ether $/ \mathrm{CH}_{2} \mathrm{Cl}_{2}$ produced prenylated phenols, dialkylated phenols and chromans in moderate yields (15-29\%, 3-11\%, 15-24\% respectively). The higher yields were found in acetylation reactions from prenylated phenols (41-98\%). 
Scheme 1. Synthesis of prenylated phenols and their acetylated derivatives in two steps.<smiles>[R]c1cc([R])c([18F])c([R3])c1[R]</smiles>

1 - 6

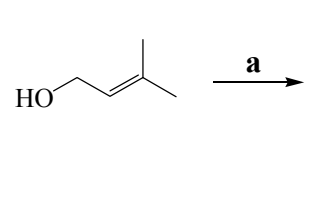

7

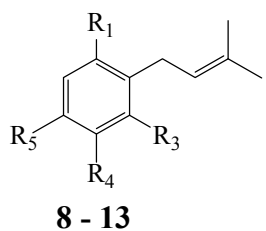

8 - 13

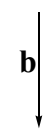

$21-26$

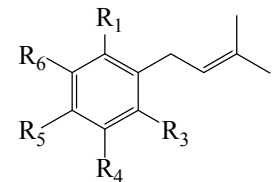

14 - 18

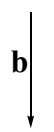

$27-31$

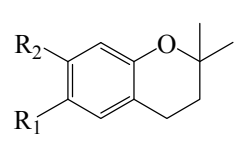

19 - 20

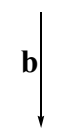

$32-33$

1.- $\mathrm{R}_{1}, \mathrm{R}_{4}=\mathrm{OH} ; \mathrm{R}_{5}=\mathrm{OCH}_{3} ; \mathrm{R}_{3}=\mathrm{H}$

19.- $\mathrm{R}_{2}=\mathrm{OH} ; \mathrm{R}_{1}=\mathrm{H}$

2.- $\mathrm{R}_{1}, \mathrm{R}_{5}=\mathrm{OH} ; \mathrm{R}_{3}, \mathrm{R}_{4}=\mathrm{H}$

3.- $\mathrm{R}_{1}, \mathrm{R}_{4}=\mathrm{OH} ; \mathrm{R}_{3}, \mathrm{R}_{5}=\mathrm{H}$

4.- $\mathrm{R}_{1}, \mathrm{R}_{5}=\mathrm{OH} ; \mathrm{R}_{3}=\mathrm{CH}_{3} ; \mathrm{R}_{4}=\mathrm{H}$

20.- $\mathrm{R}_{1}=\mathrm{OH} ; \mathrm{R}_{2}=\mathrm{H}$

21.- $\mathrm{R}_{1}, \mathrm{R}_{4}=\mathrm{OAc} ; \mathrm{R}_{5}=\mathrm{OCH}_{3} ; \mathrm{R}_{3}=\mathrm{H}$

22.- $\mathrm{R}_{1}, \mathrm{R}_{5}=\mathrm{OAc} ; \mathrm{R}_{3}, \mathrm{R}_{4}=\mathrm{H}$

5.- $\mathrm{R}_{4}, \mathrm{R}_{5}=\mathrm{OH} ; \mathrm{R}_{1}, \mathrm{R}_{3}=\mathrm{H}$

23. $-\mathrm{R}_{1}, \mathrm{R}_{4}=$ OAc; $\mathrm{R}_{3}, \mathrm{R}_{5}=\mathrm{H}$

6.- $\mathrm{R}_{1}, \mathrm{R}_{3}, \mathrm{R}_{5}=\mathrm{OH} ; \mathrm{R}_{4}=\mathrm{H}$

8. $-\mathrm{R}_{1}, \mathrm{R}_{4}=\mathrm{OH} ; \mathrm{R}_{5}=\mathrm{OCH}_{3} ; \mathrm{R}_{3}=\mathrm{H}$

24.- $\mathrm{R}_{1}, \mathrm{R}_{5}=\mathrm{OAc} ; \mathrm{R}_{3}=\mathrm{CH}_{3} ; \mathrm{R}_{4}=\mathrm{H}$

9.- $\mathrm{R}_{1}, \mathrm{R}_{5}=\mathrm{OH} ; \mathrm{R}_{3}, \mathrm{R}_{4}=\mathrm{H}$

10.- $\mathrm{R}_{1}, \mathrm{R}_{4}=\mathrm{OH} ; \mathrm{R}_{3}, \mathrm{R}_{5}=\mathrm{H}$

11.- $\mathrm{R}_{1}, \mathrm{R}_{5}=\mathrm{OH} ; \mathrm{R}_{3}=\mathrm{CH}_{3} ; \mathrm{R}_{4}=\mathrm{H}$

25.- $\mathrm{R}_{4}, \mathrm{R}_{5}=$ OAc; $\mathrm{R}_{1} \mathrm{R}_{3}=\mathrm{H}$

26.- $\mathrm{R}_{1}, \mathrm{R}_{3}, \mathrm{R}_{5}=\mathrm{OAc} ; \mathrm{R}_{4}=\mathrm{H}$

27.- $\mathrm{R}_{1}, \mathrm{R}_{5}=\mathrm{OAc} ; \mathrm{R}_{3}, \mathrm{R}_{6}=\mathrm{H} ; \mathrm{R}_{4}=$ Prenyl

12.- $\mathrm{R}_{4}, \mathrm{R}_{5}=\mathrm{OH} ; \mathrm{R}_{1}, \mathrm{R}_{3}=\mathrm{H}$

13.- $\mathrm{R}_{1}, \mathrm{R}_{3}, \mathrm{R}_{5}=\mathrm{OH} ; \mathrm{R}_{4}=\mathrm{H}$

14.- $\mathrm{R}_{1}, \mathrm{R}_{5}=\mathrm{OH} ; \mathrm{R}_{3}, \mathrm{R}_{6}=\mathrm{H} ; \mathrm{R}_{4}=$ Prenyl

28.- $\mathrm{R}_{1}, \mathrm{R}_{4}=$ OAc; $\mathrm{R}_{3}, \mathrm{R}_{6}=\mathrm{H} ; \mathrm{R}_{5}=$ Prenyl

29.- $\mathrm{R}_{1}, \mathrm{R}_{5}=\mathrm{OAc} ; \mathrm{R}_{6}=\mathrm{H} ; \mathrm{R}_{3}=\mathrm{CH}_{3}$; $\mathrm{R}_{4}=$ Prenyl

15.- $R_{1}, R_{4}=O H ; R_{3}, R_{6}=H ; R_{5}=$ Prenyl

30.- $\mathrm{R}_{4}, \mathrm{R}_{5}=$ OAc; $\mathrm{R}_{3}, \mathrm{R}_{6}=\mathrm{H} ; \mathrm{R}_{1}=$ Prenyl

16.- $\mathrm{R}_{1}, \mathrm{R}_{5}=\mathrm{OH} ; \mathrm{R}_{6}=\mathrm{H} ; \mathrm{R}_{3}=\mathrm{CH}_{3}$; $\mathrm{R}_{4}=$ Prenyl

17.- $\mathrm{R}_{4}, \mathrm{R}_{5}=\mathrm{OH} ; \mathrm{R}_{3}, \mathrm{R}_{6}=\mathrm{H} ; \mathrm{R}_{1}=$ Prenyl

31.- $\mathrm{R}_{1}, \mathrm{R}_{3}, \mathrm{R}_{5}=\mathrm{OAc} ; \mathrm{R}_{4}=\mathrm{H} ; \mathrm{R}_{6}=$ Prenyl

32.- $\mathrm{R}_{2}=\mathrm{OAc} ; \mathrm{R}_{1}=\mathrm{H}$

33.- $\mathrm{R}_{1}=\mathrm{OAc} ; \mathrm{R}_{2}=\mathrm{H}$

Conditions and reagents: (a): $\mathrm{BF}_{3} \cdot \mathrm{OEt}_{2} / \mathrm{Et}_{2} \mathrm{O}: \mathrm{CH}_{2} \mathrm{Cl}_{2}, 1: 1, \mathrm{~N}_{2}, 0-4{ }^{\circ} \mathrm{C}-$ r.t., $\rightarrow \mathbf{8}-\mathbf{1 3}(15-29 \%)+$ 14-18 (3-18\%) + 19-20 (15-24\%); (b) $\mathrm{Ac} 2 \mathrm{O} / \mathrm{DMAP} / \mathrm{CH}_{2} \mathrm{Cl}_{2}$, r.t., $\rightarrow$ 21-26 (61-98\%); $\rightarrow$ 27-31 $(43-92 \%) ; \rightarrow 32-33(41-76 \%)$.

The structures of the monoalkylated and dialkylated phenols were mainly established by ${ }^{1} \mathrm{H},{ }^{13} \mathrm{C}$, DEPT-135, gs-2D HSQC and gs-2D HMBC NMR techniques. The presence of aromatic signals in the ${ }^{1} \mathrm{H}-\mathrm{NMR}$ data spectra and their integration showed the positions of the alkylations with prenyl groups, i.e., the monoalkylated compound 9 showed a doublet at $\delta 6.92(1 \mathrm{H}, J=7.8 \mathrm{~Hz}, \operatorname{Ar} H-5)$, a doublet at $\delta$ $6.37(1 \mathrm{H}, J=8.1 \mathrm{~Hz}, \operatorname{Ar} H-6)$ and a singlet at $\delta 6.36(1 \mathrm{H}, \mathrm{Ar} H-2)$ but the dialkylated compound 14 showed a singlet at $\delta 6.78(1 \mathrm{H}, \mathrm{Ar} H-5)$ and a singlet at $\delta 6.33(1 \mathrm{H}, \mathrm{ArH}-2)$, confirming the substitution of the aromatic protons at $\mathrm{H}-4$ and $\mathrm{H}-6$ positions by prenyl groups.

It was found in results not shown that chromans were obtained mainly when equimolar amounts of catalyst were used with resorcinol (2) and hydroquinone (3) as starting material. Similar behavior was reported with other phenols [18]. The structural determination of the compounds $\mathbf{1 9}$ and $\mathbf{2 0}$ was mainly accomplished by ${ }^{1} \mathrm{H}$ - and ${ }^{13} \mathrm{C}-\mathrm{NMR}$ data spectra. The ${ }^{1} \mathrm{H}-\mathrm{NMR}$ spectrum showed the existence of aliphatic protons at $\delta=1.34(\mathbf{1 9})$ and $1.32(\mathbf{2 0})$, indicating the presence of two magnetically equivalent $\mathrm{CH}_{3}$ groups. Also two triplets at $\delta=2.70$ and 1.79 for $\mathbf{1 9}$; and $\delta=2.69$ and 1.76 for 20, indicating the existence of $\mathrm{CH}_{2}$ groups typical from chromans (C-3 and C-4). By-products were not obtained in acetylation reactions. 


\subsection{Antioxidant Activity}

The results obtained from antioxidant activities assays are shown in Table 1. All compounds were compared with Trolox ${ }^{\mathrm{TM}}$. All acetylated compounds were inactive. The prenylated phenols 8, 10, 12, 15 and 17 have antioxidant similar to Trolox ${ }^{\mathrm{TM}}$. Dialkylated compounds largely display better activities than monoalkylated compounds for the same phenol.

Table 1. Screening results of DPPH radical scavenging activity of phenols $\mathbf{1 - 6}$ and prenylated phenols derivatives $\mathbf{8}-\mathbf{3 3}$.

\begin{tabular}{cccc}
\hline Compound & $\mathbf{I C}_{\mathbf{5 0} \boldsymbol{\mu} \mathbf{M} \pm \mathbf{S D}}$ & Compound & $\mathbf{I C}_{\mathbf{5 0}} \boldsymbol{\mu} \mathbf{M} \pm \mathbf{S D}$ \\
\hline 1 & $18.56 \pm 1.55$ & 18 & $45.36 \pm 0.86$ \\
2 & $\mathrm{NA}$ & 19 & $\mathrm{NA}$ \\
3 & $28.75 \pm 2.46$ & 20 & $35.63 \pm 2.87$ \\
4 & $173.44 \pm 5.12$ & 21 & $\mathrm{NA}$ \\
5 & $22.07 \pm 0.02$ & 22 & $\mathrm{NA}$ \\
6 & $\mathrm{NA}$ & 23 & $\mathrm{NA}$ \\
8 & $23.68 \pm 0.34$ & 24 & $\mathrm{NA}$ \\
9 & $81.22 \pm 4.75$ & 25 & $\mathrm{NA}$ \\
10 & $18.68 \pm 1.48$ & 26 & $\mathrm{NA}$ \\
11 & $60.34 \pm 3.04$ & 27 & $\mathrm{NA}$ \\
12 & $21.38 \pm 1.80$ & 28 & $\mathrm{NA}$ \\
13 & $114.54 \pm 3.02$ & 29 & $\mathrm{NA}$ \\
14 & $50.94 \pm 4.29$ & 30 & $\mathrm{NA}$ \\
15 & $21.19 \pm 1.39$ & 31 & $\mathrm{NA}$ \\
16 & $48.32 \pm 1.14$ & 32 & $\mathrm{NA}$ \\
17 & $19.06 \pm 1.69$ & 33 & NA \\
Trolox & $22.04 \pm 2.11$ & & \\
\hline
\end{tabular}

Antioxidant activity are shown as $\mathrm{IC}_{50}$ values in $\mu \mathrm{M}$ concentrations; $\mathrm{NA}=$ no activity. All compounds were analyzed in triplicate and the results expressed as average \pm standard deviation.

\section{Experimental}

\subsection{General}

All chemical reagents purchased (Merck or Aldrich) were of the highest commercially available purity and were used without previous purification. Melting points $\left(\mathrm{mp}:{ }^{\circ} \mathrm{C}\right)$ were measured on a melting point apparatus Stuart-Scientific SMP3 and are uncorrected. IR spectra were recorded as a methylene chloride solution or $\mathrm{KBr}$ disk (compound 13) in a Thermo Scientific Nicolet 6700 FT-IR spectrometer and frequencies are reported in $\mathrm{cm}^{-1}$. Low resolution mass spectra were recorded on a Thermo Scientific, Trace GC Ultra, ISQ mass spectrometer at $70 \mathrm{eV}$ ionizing voltage and are given as $m / z$ (\% rel. int.) and these were measured in acetylated derivatives only. ${ }^{1} \mathrm{H}-,{ }^{13} \mathrm{C}$-(DEPT 135 and DEPT 90), HSQC and 2D HMBC spectra were recorded in $\mathrm{CDCl}_{3}$ solutions and referenced to the residual peaks of $\mathrm{CHCl}_{3}$ at $\delta 7.26 \mathrm{ppm}$ and $\delta 77.0 \mathrm{ppm}$ for ${ }^{1} \mathrm{H}$ and ${ }^{13} \mathrm{C}$, respectively, on a Bruker Avance 400 Digital NMR spectrometer, operating at $400.1 \mathrm{MHz}$ for ${ }^{1} \mathrm{H}$ and $100.6 \mathrm{MHz}$ for ${ }^{13} \mathrm{C}$. Chemical shifts are reported in $\delta$ ppm and coupling constants $(J)$ are given in Hz. Silica gel (Merck 
200-300 mesh) was used for C.C. and silica gel plates HF-254 for TLC. TLC spots were detected by both under UV lamp and heating after spraying with $25 \% \mathrm{H}_{2} \mathrm{SO}_{4}$ in $\mathrm{H}_{2} \mathrm{O}$. Antioxidant determinations were performed in a Thermo Scientific Multiskan FC 96-well plate photometer.

\subsection{General Procedure for Preparation of Prenylated Phenols}

A solution of phenol $(4.5 \mathrm{mmol})$ and 3-methyl-2-buten-1-ol $(7,9.0 \mathrm{mmol})$ was placed in a round bottom flask and dissolved in dry 1:1 ethyl ether-dichloromethane $(25 \mathrm{~mL})$. Under nitrogen gas and with vigorous stirring, a solution of $\mathrm{BF}_{3}$ etherate $(0.9 \mathrm{mmol})$ in dry $1: 1$ ethyl ether-dichloromethane $(10 \mathrm{~mL})$ was added dropwise to the solution cooled to $0-5^{\circ} \mathrm{C}$. Then the reaction mixture was allowed to warm up to room temperature and the stirring continued. After $48 \mathrm{~h}$, milled ice was added to the reaction mixture and it was extracted with methylene chloride. Then, the organic layer was separated and a new extraction with ethyl acetate was done. The organic solutions obtained after extractions were mixed and dried over anhydrous sodium sulphate and filtered, the solvent was evaporated under reduced pressure. After, the mixture was subjected to silica gel flash column chromatography (ethyl acetate, petroleum ether) to obtain pure products.

\subsubsection{1,4-Dihydroxy-2-methoxy-5-(3-methyl-2-buten-1-yl) Benzene (8)}

Compound 8 was obtained from 2-methoxy-1,4-dihydroxybenzene (1) as described above. The crude mixture was purified using petroleum ether-ethyl acetate (80:20) as the mobile phase to afford the title compound as an orange solid (126 mg, 24\%); mp: 102-103 ${ }^{\circ} \mathrm{C}$; IR (solution): $v_{\max } 3210(\mathrm{OH}), 1621$ $\left(\mathrm{C}=\mathrm{C}\right.$ aromatic), 1434, 1190; ${ }^{1} \mathrm{H}-\mathrm{NMR}\left(\mathrm{CDCl}_{3}\right): 6.67$ (s, 1H, $\left.\mathrm{ArH}-6\right) ; 6.43$ (s, 1H, ArH-3); 5.28 (br. t, $\left.J=7.2 \mathrm{~Hz}, 1 \mathrm{H}, \mathrm{CCHCH}_{2}\right) ; 5.13(\mathrm{~s}, 1 \mathrm{H}, \mathrm{ArC}-1-\mathrm{OH}) 4.79$ (s, 1H, ArC-4-OH); 3.43 (s, 3H, ArC-2$\left.\mathrm{OCH}_{3}\right) ; 3.25\left(\mathrm{~d}, J=7.2 \mathrm{~Hz}, 2 \mathrm{H}, \mathrm{C}=\mathrm{CHCH}_{2}\right) ; 1.77$ [s, 6H, CHC(CH$\left.)_{2}\right] ;{ }^{13} \mathrm{C}-\mathrm{NMR}\left(\mathrm{CDCl}_{3}\right): 17.8$ $\left(\mathrm{CH}_{3} \mathrm{CH}_{3} \mathrm{C}=\mathrm{CH}_{2}-\right) ; 25.7\left(\mathrm{CH}_{3} \mathrm{CH}_{3} \mathrm{C}=\mathrm{CH}_{2}-\right) ; 29.3\left(\mathrm{CCHCH}_{2}-\right) ; 56.1\left(\mathrm{CH}_{3} \mathrm{O}-\right) ; 100.3(\mathrm{ArCH}-3) ; 115.3$ $(\mathrm{ArCH}-6) ; 118.5(\mathrm{ArC}-5) ; 121.9\left(\mathrm{C}=\mathrm{CHCH}_{2}\right) ; 134.8\left(\mathrm{C}=\mathrm{CHCH}_{2}\right) ; 139.3(\mathrm{ArC}-1) ; 145.4(\mathrm{ArC}-2)$; 147.5 (ArC-4).

\subsubsection{1,3-Dihydroxy-4-(3-methyl-2-buten-1-yl) Benzene (9)}

Compound 9 was obtained from resorcinol (2) as described above. The crude mixture was purified using petroleum ether-ethyl acetate (70:30) as the mobile phase to afford compound 9 as an orange semi-solid (186.4 mg, 23\%); IR (solution): $v_{\max } 3362(\mathrm{OH}), 2968$ (alkane C-H), 2912 (C-H alkane), $1604\left(\mathrm{C}=\mathrm{C}\right.$ aromatic), 1518, 1451, 1157; ${ }^{1} \mathrm{H}-\mathrm{NMR}\left(\mathrm{CDCl}_{3}\right): 6.92(\mathrm{~d}, 1 \mathrm{H}, J=7.8 \mathrm{~Hz}, \mathrm{ArH}-5) ; 6.37$ (d, $1 \mathrm{H}, J=8.1 \mathrm{~Hz}, \mathrm{ArH}-6$ ); 6.36 (s, $1 \mathrm{H}, \mathrm{ArH}-2) ; 5.29$ (br. t, $J=6.7 \mathrm{~Hz}, 1 \mathrm{H}, \mathrm{CCHCH}_{2}$ ); 3.26 (d, $J=7.0 \mathrm{~Hz}$,

$\left.2 \mathrm{H}, \mathrm{C}=\mathrm{CHCH}_{2}\right) ; 1.75\left(\mathrm{~s}, 3 \mathrm{H}, \mathrm{CHCCH}_{3} \mathrm{CH}_{3}\right) ; 1.74\left(\mathrm{~s}, 3 \mathrm{H}, \mathrm{CHCCH}_{3} \mathrm{CH}_{3}\right) .{ }^{13} \mathrm{C}-\mathrm{NMR}\left(\mathrm{CDCl}_{3}\right): 17.7$ $\left(\mathrm{CH}_{3} \mathrm{CH}_{3} \mathrm{C}=\mathrm{CH}_{2}-\right) ; 25.7\left(\mathrm{CH}_{3} \mathrm{CH}_{3} \mathrm{C}=\mathrm{CH}_{2}-\right) ; 28.7\left[\left(\mathrm{CH}_{3}\right)_{2} \mathrm{CCHCH}_{2}-\right] ; 103.3(\mathrm{ArC}-2) ; 107.7$ (ArC-6); $119.6(\mathrm{ArC}-4) ; 122.2\left[\left(\mathrm{CH}_{3}\right)_{2} \mathrm{C}=\mathrm{CHCH}_{2}\right] ; 130.5(\mathrm{ArC}-5) ; 134.2\left[\left(\mathrm{CH}_{3}\right)_{2} \mathrm{C}=\mathrm{CHCH}_{2}\right] ; 154.6(\mathrm{ArC}-1)$; 154.7 (ArC-3). 


\subsubsection{1,4-Dihydroxy-2-(3-methyl-2-buten-1-yl) Benzene (10)}

Compound 10 was obtained from hydroquinone (3) as described above. The crude mixture was purified using petroleum ether-ethyl acetate $(80: 20)$ as the mobile phase to afford compound $\mathbf{1 0}$ as colorless needles (165.8 mg, 21\%); mp: 102-104 ${ }^{\circ} \mathrm{C}$, lit. [19], 100-101 ${ }^{\circ} \mathrm{C}$; IR (solution): $v_{\max } 3228$ (OH), 1654 (C=C Aromatic), 1560, 1452, 1194; ${ }^{1} \mathrm{H}-\mathrm{NMR}\left(\mathrm{CDCl}_{3}\right): 6.68$ (d, 1H, J=8.5 Hz, ArH-6); 6.61 (d, $1 \mathrm{H}, J=3.0 \mathrm{~Hz}, \mathrm{Ar} H-3$ ); 6.58 (dd, $J=8.4$ and $3.0 \mathrm{~Hz}, 1 \mathrm{H}, \operatorname{Ar} H-5$ ); 5.29 (br. t, $J=7.3 \mathrm{~Hz}, 1 \mathrm{H}$, $\left.\mathrm{C}=\mathrm{CHCH}_{2}\right) ; 3.29\left(\mathrm{~d}, J=7.2 \mathrm{~Hz}, 2 \mathrm{H}, \mathrm{C}=\mathrm{CHCH}_{2}\right) ; 1.77$ [s, 6H, $\left.\mathrm{CHC}\left(\mathrm{CH}_{3}\right)_{2}\right] ;{ }^{13} \mathrm{C}-\mathrm{NMR}\left(\mathrm{CDCl}_{3}\right): 17.8$ $\left(\mathrm{CH}_{3} \mathrm{CH}_{3} \mathrm{C}=\mathrm{CH}-\right) ; 25.8\left(\mathrm{CH}_{3} \mathrm{CH}_{3} \mathrm{C}=\mathrm{CH}-\right) ; 29.7\left[\left(\mathrm{CH}_{3}\right)_{2} \mathrm{CCHCH}_{2}-\right] ; 113.7$ (ArC-5); $116.4(\operatorname{ArC}-6)$; $116.6(\mathrm{ArC}-3) ; 121.4\left(\left(\mathrm{CH}_{3}\right)_{2} \mathrm{C}=\mathrm{CHCH}_{2}\right) ; 128.2(\mathrm{ArC}-2) ; 134.9\left[\left(\mathrm{CH}_{3}\right)_{2} \mathrm{C}=\mathrm{CHCH}_{2}\right] ; 148.1(\mathrm{ArC}-1)$; $149.3(\mathrm{ArC}-4)$.

\subsubsection{1,3-Dihydroxy-5-methyl-4-(3-methyl-2-buten-1-yl) Benzene (11)}

Compound 11 was obtained from orcinol (4) as described above. The crude mixture was purified using petroleum ether-ethyl acetate (70:30) as the mobile phase to afford compound $\mathbf{1 1}$ as a reddish semi-solid (215.4 mg, 29\%); IR (solution): $v_{\max } 3218$ (OH), 2964 (C-H alkane), 2923 (C-H alkane), $1610\left(\mathrm{C}=\mathrm{C}\right.$ aromatic), 1474, 1318, 1142; ${ }^{1} \mathrm{H}-\mathrm{NMR}\left(\mathrm{CDCl}_{3}\right): 6.26(\mathrm{~d}, 1 \mathrm{H}, J=2.0 \mathrm{~Hz}, \mathrm{ArH}-2) ; 6.21(\mathrm{~d}$, $1 \mathrm{H}, J=2.1 \mathrm{~Hz}, \mathrm{ArH}-6) ; 5.14\left(\mathrm{~m}, 2 \mathrm{H}, \mathrm{OH}, \mathrm{C}=\mathrm{CHCH}_{2}\right) ; 4.65(\mathrm{~s}, 1 \mathrm{H}, \mathrm{OH}) 3.28(\mathrm{~d}, J=6.8 \mathrm{~Hz}, 2 \mathrm{H}$, $\left.\mathrm{C}=\mathrm{CHCH}_{2}\right) ; 2.23\left(\mathrm{~s}, 3 \mathrm{H}, \mathrm{Ar}-\mathrm{CH}_{3}\right) ; 1.80\left(\mathrm{~s}, 3 \mathrm{H}, \mathrm{CH}_{3} \mathrm{CH}_{3} \mathrm{C}=\mathrm{CH}_{2}-\right) ; 1.73\left(\mathrm{~s}, 3 \mathrm{H}, \mathrm{CH}_{3} \mathrm{CH}_{3} \mathrm{C}=\mathrm{CH}_{2}-\right)$; ${ }^{13} \mathrm{C}-\mathrm{NMR}\left(\mathrm{CDCl}_{3}\right)$ : $17.9\left(\mathrm{CH}_{3} \mathrm{CH}_{3} \mathrm{C}=\mathrm{CH}-\right) ; 20.1 \quad\left(\mathrm{CH}_{3} \mathrm{CH}_{3} \mathrm{C}=\mathrm{CH}-\right) ; 25.2 \quad\left[\left(\mathrm{CH}_{3}\right)_{2} \mathrm{CCHCH}_{2}-\right] ; 25.7$ $\left(\mathrm{Ar}-\mathrm{CH}_{3}-5\right) ; 101.0$ (ArCH-2); 109.7 (ArCH-6) $117.9(\mathrm{ArC}-4) ; 122.1 \quad\left[\left(\mathrm{CH}_{3}\right)_{2} \mathrm{C}=\mathrm{CHCH}_{2}\right] ; 133.9$ $\left[\left(\mathrm{CH}_{3}\right)_{2} \mathrm{C}=\mathrm{CHCH}_{2}\right] ; 138.5(\mathrm{ArC}-5) ; 154.2(\mathrm{ArC}-1) ; 155.3(\mathrm{ArC}-3)$.

\subsubsection{1,2-Dihydroxy-4-(3-methyl-2-buten-1-yl) Benzene (12)}

Compound 12 was obtained from pyrocatechol (5) as described above. The crude mixture was purified using petroleum ether-ethyl acetate (70:30) as the mobile phase to afford compound $\mathbf{1 2}$ as a colorless solid (201.9 mg, 25\%); mp: 58-61 ${ }^{\circ} \mathrm{C}$; IR (solution): $v_{\max } 3364(\mathrm{OH}), 2924$ (C-H alkane), 2853 (C-H alkane), 1603 (C=C aromatic), 1518, 1452, 1376, 1280; ${ }^{1} \mathrm{H}-\mathrm{NMR}\left(\mathrm{CDCl}_{3}\right): 6.77(\mathrm{~d}, 1 \mathrm{H}$, $J=8.1 \mathrm{~Hz}, \operatorname{Ar} H-6) ; 6.70(\mathrm{~d}, 1 \mathrm{H}, J=1.3 \mathrm{~Hz}, \operatorname{Ar} H-3) ; 6.61(\mathrm{dd}, 1 \mathrm{H}, J=7.4 \mathrm{~Hz}$ and $1.2 \mathrm{~Hz}, \operatorname{Ar} H-5) ; 5.45$ $(\mathrm{s}, 1 \mathrm{H}, \mathrm{OH}) 5.37(\mathrm{~s}, 1 \mathrm{H}, \mathrm{OH}) ; 5.28$ (br. t, $\left.J=7.3 \mathrm{~Hz}, 1 \mathrm{H}, \mathrm{CCHCH}_{2}\right) ; 3.22(\mathrm{~d}, J=7.8 \mathrm{~Hz}, 2 \mathrm{H}$, $\left.\mathrm{C}=\mathrm{CHCH}_{2}\right) ; 1.74\left(\mathrm{~s}, 3 \mathrm{H}, \mathrm{CHCCH}_{3} \mathrm{CH}_{3}\right) ; 1.70\left(\mathrm{~s}, 3 \mathrm{H}, \mathrm{CHCCH}_{3} \mathrm{CH}_{3}\right) ;{ }^{13} \mathrm{C}-\mathrm{NMR}\left(\mathrm{CDCl}_{3}\right): 17.7$ $\left(\mathrm{CH}_{3} \mathrm{CH}_{3} \mathrm{C}=\mathrm{CH}_{2}-\right) ; 25.7\left(\mathrm{CH}_{3} \mathrm{CH}_{3} \mathrm{C}=\mathrm{CH}_{2}-\right) ; 33.5\left[\left(\mathrm{CH}_{3}\right)_{2} \mathrm{CCHCH}_{2}-\right] ; 115.4(\mathrm{ArC}-3) ; 115.5(\operatorname{ArC}-5)$; 120.7 (ArC-5); $123.3\left[\left(\mathrm{CH}_{3}\right)_{2} \mathrm{C}=\mathrm{CHCH}_{2}\right] ; 132.4\left[\left(\mathrm{CH}_{3}\right)_{2} \mathrm{C}=\mathrm{CHCH}_{2}\right] ; 135.1$ (ArC-4); 141.3 (ArC-1); 143.4 (ArC-2).

\subsubsection{1,3,5-Trihydroxy-2-(3-methyl-2-buten-1-yl) Benzene (13)}

Compound 13 was obtained from phloroglucinol (6) as described above. The crude mixture was purified using petroleum ether-ethyl acetate (45:55) as the mobile phase to afford compound $\mathbf{1 3}$ as a reddish semi-solid (117.3 mg, 15\%); IR (KBr): $v_{\max } 3391(\mathrm{OH}), 2974$ (C-H alkane), 2926 (C-H alkane), $1616\left(\mathrm{C}=\mathrm{C}\right.$ aromatic), 1517, 1465, 1375, 1284, 1230, 1144; ${ }^{1} \mathrm{H}-\mathrm{NMR}\left[\left(\mathrm{CD}_{3}\right)_{2} \mathrm{CO}\right]: 7.95$ (s, 2H, Ar-1,3-OH) 5.93 (s, 2H, $\mathrm{ArH}-4,6) ; 5.24$ (br. t, $\left.1 \mathrm{H}, J=7.1 \mathrm{~Hz}, \mathrm{C}=\mathrm{CHCH}_{2}\right) ; 3.22(\mathrm{~d}, J=7.1 \mathrm{~Hz}$, 
$\left.2 \mathrm{H}, \mathrm{C}=\mathrm{CHCH}_{2}\right) ; 1.71\left(\mathrm{~s}, 3 \mathrm{H}, \mathrm{CH}_{3} \mathrm{CH}_{3} \mathrm{C}=\mathrm{CH}_{2}-\right) ; 1.60\left(\mathrm{~s}, 3 \mathrm{H}, \mathrm{CH}_{3} \mathrm{CH}_{3} \mathrm{C}=\mathrm{CH}_{2}-\right) ;{ }^{13} \mathrm{C}-\mathrm{NMR}\left[\left(\mathrm{CD}_{3}\right)_{2} \mathrm{CO}\right]$ : $17.5\left(\mathrm{CH}_{3} \mathrm{CH}_{3} \mathrm{C}=\mathrm{CH}-\right) ; 22.2\left[\left(\mathrm{CH}_{3}\right)_{2} \mathrm{CCHCH}_{2}-\right] ; 25.5\left(\mathrm{CH}_{3} \mathrm{CH}_{3} \mathrm{C}=\mathrm{CH}-\right) ; 95.0(\mathrm{ArCH}-4,6) ; 106.9(\operatorname{ArC}-2)$; $125.0\left[\left(\mathrm{CH}_{3}\right)_{2} \mathrm{C}=\mathrm{CHCH}_{2}-\right] ; 129.5\left[\left(\mathrm{CH}_{3}\right)_{2} \mathrm{C}=\mathrm{CHCH}_{2}\right] ; 156.6(\mathrm{ArC}-5) ; 157.0((\mathrm{ArC}-1,3)$.

\subsubsection{1,3-Dihydroxy-4,6-di(3-methyl-2-buten-1-yl) Benzene (14)}

Compound 14 was a by-product from the reaction to obtain 9 and was isolated using petroleum ether-ethyl acetate (70:30) as the mobile phase to afford compound $\mathbf{1 4}$ as a reddish oil (123.7 $\mathrm{mg}$, 11\%); IR (solution): $v_{\max } 3419(\mathrm{OH}), 2969,2914,2857$ (C-H alkanes), 1620 (C=C aromatic), 1507, 1440, 1376, 1300, 1272, 1207, 1162, 1078; ${ }^{1} \mathrm{H}-\mathrm{NMR}\left(\mathrm{CDCl}_{3}\right): 6.78$ (s, 1H, $\left.\mathrm{ArH}-5\right) ; 6.33(\mathrm{~s}, 1 \mathrm{H}$, $\mathrm{ArH}-2$ ); 5.29 (br. t, $J=6.5 \mathrm{~Hz}, 2 \mathrm{H}, 2 \times \mathrm{CCHCH}_{2}$ ); 5.10 (s, 2H, Ar-1,3-OH) 3.26 (d, $J=7.1 \mathrm{~Hz}, 4 \mathrm{H}$, $\left.2 \times \mathrm{C}=\mathrm{CHCH}_{2}\right) ; 1.77\left(\mathrm{~s}, 6 \mathrm{H}, 2 \times \mathrm{CHCCH}_{3} \mathrm{CH}_{3}\right) ; 1.76\left(\mathrm{~s}, 6 \mathrm{H}, 2 \times \mathrm{CHCCH}_{3} \mathrm{CH}_{3}\right) ;{ }^{13} \mathrm{C}-\mathrm{NMR}\left(\mathrm{CDCl}_{3}\right)$ : $17.8\left(\mathrm{CH}_{3} \mathrm{CH}_{3} \mathrm{C}=\mathrm{CH}_{2}-\right) ; 25.8\left(\mathrm{CH}_{3} \mathrm{CH}_{3} \mathrm{C}=\mathrm{CH}_{2}-\right) ; 29.3 \quad\left[\left(\mathrm{CH}_{3}\right)_{2} \mathrm{CCHCH}_{2}-\right] ; 103.7$ (ArC-2); 118.7.7 $(\mathrm{ArC}-4,6) ; 122.4\left[\left(\mathrm{CH}_{3}\right)_{2} \mathrm{C}=\mathrm{CHCH}_{2}\right] ; 130.9(\mathrm{ArC}-5) ; 134.4\left[\left(\mathrm{CH}_{3}\right)_{2} \mathrm{C}=\mathrm{CHCH}_{2}\right] ; 153.6(\mathrm{ArC}-1,3)$.

\subsubsection{1,4-Dihydroxy-2,5-di(3-methyl-2-buten-1-yl) Benzene (15)}

Compound 15 was a by-product from the reaction to obtain $\mathbf{1 0}$ and was purified using petroleum ether-ethyl acetate (80:20) as the mobile phase to afford compound $\mathbf{1 5}$ as a colorless semi-solid, $34 \mathrm{mg}, 3 \%$; IR (solution): $v_{\max } 3223(\mathrm{OH}), 2978,2926$ (C-H alkanes), 1431, 1373, 1242, 1186; ${ }^{1} \mathrm{H}-\mathrm{NMR}\left(\mathrm{CDCl}_{3}\right): 6.57$ (s, 2H, $\left.\mathrm{ArH}-3,6\right) ; 5.28$ (br. t, $\left.J=7.2 \mathrm{~Hz}, 2 \mathrm{H}, 2 \times \mathrm{C}=\mathrm{CHCH}_{2}\right) ; 3.26(\mathrm{~d}, J=7.2 \mathrm{~Hz}$, $\left.\left.4 \mathrm{H}, 2 \times \mathrm{C}=\mathrm{CHCH}_{2}\right) ; 1.76\left[\mathrm{~s}, 12 \mathrm{H}, 2 \times \mathrm{CHC}\left(\mathrm{CH}_{3}\right)_{2}\right)\right] ;{ }^{13} \mathrm{C}-\mathrm{NMR}\left(\mathrm{CDCl}_{3}\right): 17.8\left(\mathrm{CH}_{3} \mathrm{CH}_{3} \mathrm{C}=\mathrm{CH}-\right) ; 25.8$ $\left(\mathrm{CH}_{3} \mathrm{CH}_{3} \mathrm{C}=\mathrm{CH}-\right) ; 29.4\left[\left(\mathrm{CH}_{3}\right)_{2} \mathrm{CCHCH}_{2}-\right] ; 116.9(\mathrm{ArC}-3,6) ; 121.7\left[\left(\mathrm{CH}_{3}\right)_{2} \mathrm{C}=\mathrm{CHCH}_{2}\right] ; 125.7(\mathrm{ArC}-2,5)$; 134.6 $\left[\left(\mathrm{CH}_{3}\right)_{2} \mathrm{C}=\mathrm{CHCH}_{2}\right] ; 147.9(\mathrm{ArC}-1,4)$.

\subsubsection{1,3-Dihydroxy-5-methyl-4,6-di(3-methyl-2-buten-1-yl) Benzene (16)}

Compound 16 was a by-product from the reaction to obtain 11 and was purified using petroleum ether-ethyl acetate (70:30) as the mobile phase to afford compound $\mathbf{1 6}$ as a pale yellow semi-solid (174.3 mg, 17\%); IR (solution): $v_{\max } 3421(\mathrm{OH}), 2969,2914,2857$ (C-H alkanes), $1601 \quad(\mathrm{C}=\mathrm{C}$ aromatic), 1445, 1375, 1324, 1270, 1209, 1158, 1084; ${ }^{1} \mathrm{H}-\mathrm{NMR}\left(\mathrm{CDCl}_{3}\right): 6.23$ (s, 1H, ArH-2); 5.12 (br. t, $\left.J=6.7 \mathrm{~Hz}, 2 \mathrm{H}, 2 \times \mathrm{C}=\mathrm{CHCH}_{2}\right) ; 5.02(\mathrm{~s}, 2 \mathrm{H}, \operatorname{Ar}-1,3-\mathrm{OH}) ; 3.33(\mathrm{~d}, J=6.7 \mathrm{~Hz}, 4 \mathrm{H}$, $\left.2 \times \mathrm{C}=\mathrm{CHCH}_{2}\right) ; 2.22$ (s, 3H, $\left.\mathrm{Ar}-\mathrm{CH}_{3}\right) ; 1.80\left(\mathrm{~s}, 6 \mathrm{H}, 2 \times \mathrm{CH}_{3} \mathrm{CH}_{3} \mathrm{C}_{2}=\mathrm{CH}_{2}\right) ; 1.72 \quad(\mathrm{~s}, 6 \mathrm{H}$, $\left.2 \times \quad \mathrm{CH}_{3} \mathrm{CH}_{3} \mathrm{C}=\mathrm{CH}_{2}-\right) .{ }^{13} \mathrm{C}-\mathrm{NMR} \quad\left(\mathrm{CDCl}_{3}\right) ; 15.8 \quad\left(\mathrm{Ar}-\mathrm{CH}_{3}-5\right) ; 17.9 \quad\left(\mathrm{CH}_{3} \mathrm{CH}_{3} \mathrm{C}=\mathrm{CH}-\right) ; 25.6$ $\left[\left(\mathrm{CH}_{3}\right)_{2} \mathrm{CCHCH}_{2-}\right] ; \quad 25.7 \quad\left(\mathrm{CH}_{3} \mathrm{CH}_{3} \mathrm{C}=\mathrm{CH}-\right) ; \quad 101.2 \quad(\mathrm{ArCH}-2) ; \quad 118.6 \quad(\mathrm{ArC}-4,6) ; \quad 122.6$ $\left.\left[\mathrm{CH}_{3}\right)_{2} \mathrm{C}=\mathrm{CHCH}_{2}\right] ; 133.0\left[\left(\mathrm{CH}_{3}\right)_{2} \mathrm{C}=\mathrm{CHCH}_{2}\right] ; 136.4(\mathrm{ArC}-5) 152.7(\mathrm{ArC}-1,3)$.

\subsubsection{1,2-Dihydroxy-4,5-di(3-methyl-2-buten-1-yl) Benzene (17)}

Compound 17 was a by-product from the reaction to obtain 12 and was purified using petroleum ether-ethyl acetate (70:30) as the mobile phase to afford compound $\mathbf{1 7}$ as a reddish semi-solid (198.7 mg, 18\%); IR (solution): $v_{\max } 3388(\mathrm{OH}), 2970,2914,2856$ (C-H alkane), 1607 (C=C aromatic), 1514, 1477, 1448, 1375, 1282; ${ }^{1} \mathrm{H}-\mathrm{NMR}\left(\mathrm{CDCl}_{3}\right): 6.66$ (s, 2H, $\left.\mathrm{ArH}-3,6\right) ; 5.47$ (br. s, 2H, OH); 5.20 (br. t, $\left.J=6.9 \mathrm{~Hz}, 2 \mathrm{H}, 2 \times \mathrm{C}=\mathrm{CHCH}_{2}\right) ; 3.19\left(\mathrm{~d}, J=7.1 \mathrm{~Hz}, 4 \mathrm{H}, 2 \times \mathrm{C}=\mathrm{CHCH}_{2}\right) ; 1.72(\mathrm{~s}, 6 \mathrm{H}$, 
$\left.2 \times \mathrm{CHCCH}_{3} \mathrm{CH}_{3}\right) ; 1.67\left(\mathrm{~s}, 6 \mathrm{H}, 2 \times \mathrm{CHCCH}_{3} \mathrm{CH}_{3}\right) ;{ }^{13} \mathrm{C}-\mathrm{NMR}\left(\mathrm{CDCl}_{3}\right): 17.8\left(\mathrm{CH}_{3} \mathrm{CH}_{3} \mathrm{C}=\mathrm{CH}_{2}-\right) ; 25.7$ $\left(\mathrm{CH}_{3} \mathrm{CH}_{3} \mathrm{C}=\mathrm{CH}_{2}-\right) ; 30.8 \quad\left[\left(\mathrm{CH}_{3}\right)_{2} \mathrm{CCHCH}_{2}-\right] ; 116.1 \quad(\mathrm{ArC}-3,6) ; 123.1 \quad\left[\left(\mathrm{CH}_{3}\right)_{2} \mathrm{C}=\mathrm{CHCH}_{2}\right] ; 132.2$ $\left[\left(\mathrm{CH}_{3}\right)_{2} \mathrm{C}=\mathrm{CHCH}_{2}\right] ; 141.3(\mathrm{ArC}-1,2)$.

\subsubsection{1,3,5-Trihydroxy-2,6-di(3-methyl-2-buten-1-yl) Benzene (18)}

Compound 18 was a by-product from the reaction to obtain 13 and was purified using petroleum ether-ethyl acetate (45:55) as the mobile phase to afford compound $\mathbf{1 8}$ as a reddish oil $(116.7 \mathrm{mg}$, 11\%); IR (solution): $v_{\max } 3434(\mathrm{OH}), 2971,2915,2857$ (C-H alkanes), 1623 (C=C aromatic), 1508, 1449, 1375, 1260, 1226, 1168, 1085; ${ }^{1} \mathrm{H}-\mathrm{NMR}\left(\mathrm{CDCl}_{3}\right): 5.95$ (s, 1H, $\left.\mathrm{ArH}-4\right) ; 5.23$ (br. t, 2H, $J=6.9 \mathrm{~Hz}$, $\left.2 \times \mathrm{C}=\mathrm{CHCH}_{2}\right) ; 3.33\left(\mathrm{~d}, J=7.0 \mathrm{~Hz}, 4 \mathrm{H}, 2 \times \mathrm{C}=\mathrm{CHCH}_{2}\right) ; 1.80\left(\mathrm{~s}, 6 \mathrm{H}, 2 \times \mathrm{CH}_{3} \mathrm{CH}_{3} \mathrm{C}=\mathrm{CH}_{2}-\right) ; 1.74$ (s, 6H, $\left.2 \times \mathrm{CH}_{3} \mathrm{CH}_{3} \mathrm{C}=\mathrm{CH}_{2}-\right) ;{ }^{13} \mathrm{C}-\mathrm{NMR}\left(\mathrm{CDCl}_{3}\right): 17.8\left(\mathrm{CH}_{3} \mathrm{CH}_{3} \mathrm{C}=\mathrm{CH}-\right) ; 22.3\left[\left(\mathrm{CH}_{3}\right)_{2} \mathrm{CCHCH}_{2}-\right]$; $25.7 \quad\left(\mathrm{CH}_{3} \mathrm{CH}_{3} \mathrm{C}=\mathrm{CH}-\right) ; 96.0 \quad(\mathrm{ArCH}-4) ; 106.2 \quad(\mathrm{ArC}-2,6) ; 122.3 \quad\left[\left(\mathrm{CH}_{3}\right)_{2} \mathrm{C}=\mathrm{CHCH}_{2}-\right] ; 134.9$ $\left[\left(\mathrm{CH}_{3}\right)_{2} \mathrm{C}=\mathrm{CHCH}_{2}\right] ; 153.0(\mathrm{ArC}-3,5) ; 15.0(\mathrm{ArC}-1)$.

\subsubsection{7-Hydroxy-2,2-dimethyl-chroman (19)}

Compound 19was a by-product from the reaction to obtain 9 and was purified using petroleum ether-ethyl acetate (70:30) as the mobile phase to afford compound $\mathbf{1 9}$ as a pale yellow oil (123.8 $\mathrm{mg}$, 15\%); IR (solution): $v_{\max } 3393(\mathrm{OH}), 2975,2932,2852$ (C-H alkanes), 1622 (C=C aromatic), 1594, 1508, 1461, 1369, 1296, 1226, 1149, 1119; ${ }^{1} \mathrm{H}-\mathrm{NMR}\left(\mathrm{CDCl}_{3}\right): 6.90$ (d, 1H, J=8.2 Hz, ArH-5); 6.38 $\left(\mathrm{dd}, 1 \mathrm{H}, J_{o}=8.1 \mathrm{~Hz}, J_{m}=2.4 \mathrm{~Hz}, \operatorname{ArH}-6\right) ; 6.34$ (d, 1H, $\left.J_{m}=2.2 \mathrm{~Hz}, \mathrm{ArH}-8\right) ; 6.20$ (s, 1H, Ar-7-OH);

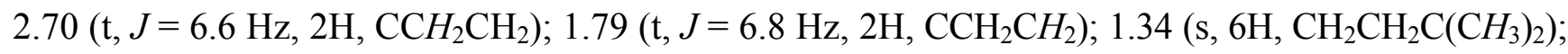

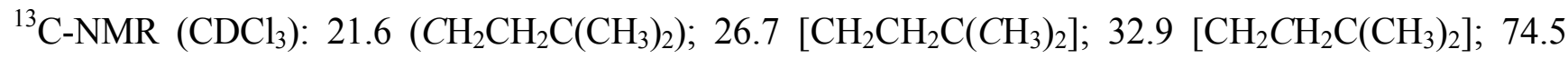
$\left[\mathrm{CH}_{2} \mathrm{CH}_{2} \mathrm{C}\left(\mathrm{CH}_{3}\right)_{2}\right] ; 103.7$ (ArCH-8); 107.6 (ArCH-6); 113.0 (ArC-4a); 130.0 (ArCH-5) 154.4 (ArC-8a); 154.9 (ArC-7).

\subsubsection{6-Hydroxy-2,2-dimethyl-chroman (20)}

Compound 20 was a by-product from the reaction to obtain $\mathbf{1 0}$ and was purified using petroleum ether-ethyl acetate (80:20) as the mobile phase to afford compound $\mathbf{2 0}$ as a reddish oil, $194.6 \mathrm{mg}, 24 \%$; IR (solution): $v_{\max } 3387(\mathrm{OH}), 2974,2931,2850$ (C-H alkanes), 1618 (C=C aromatic), 1492, 1449, 1369, 1452, 1243, 1200; ${ }^{1} \mathrm{H}-\mathrm{NMR}\left(\mathrm{CDCl}_{3}\right)$ : 6.66-6.57 (m, 3H, ArH-5,7,8); 6.13 (s, 1H, Ar-6-OH);

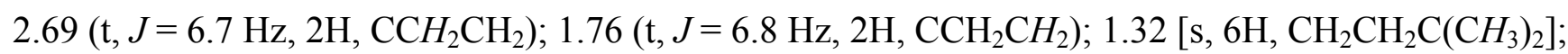
${ }^{13} \mathrm{C}-\mathrm{NMR}\left(\mathrm{CDCl}_{3}\right): 22.5\left[\mathrm{CH}_{2} \mathrm{CH}_{2} \mathrm{C}\left(\mathrm{CH}_{3}\right)_{2}\right] ; 26.6\left[\mathrm{CH}_{2} \mathrm{CH}_{2} \mathrm{C}\left(\mathrm{CH}_{3}\right)_{2}\right] ; 32.7\left[\mathrm{CH}_{2} \mathrm{CH}_{2} \mathrm{C}\left(\mathrm{CH}_{3}\right)_{2}\right] ; 73.9$ $\left[\mathrm{CH}_{2} \mathrm{CH}_{2} \mathrm{C}\left(\mathrm{CH}_{3}\right)_{2}\right] ; 114.5$ (ArCH-5); 115.5 (ArCH-7); 117.6 (ArCH-8), 121.7 (ArC-4a); 147.5 (ArC-8a); 148.6 (ArC-6).

\subsection{General Procedure for the Acetylation Reactions}

To a stirred solution of prenylated phenol (1 equiv.) in methylene chloride $(10 \mathrm{~mL})$ was added dimethylaminopyridine ( 0.1 equiv.) and acetic anhydride (4 equiv.) at room temperature. After $1 \mathrm{~h}$, the solvent was evapored under reduced pressure. Finally, the mixture was subjected to silica gel flash column chromatography (ethyl acetate, petroleum ether) to obtain pure products. 


\subsubsection{1,4-Diacetoxy-2-metoxi-5-(3-methyl-2-buten-1-yl) Benzene (21)}

Compound 21 was obtained from 8 as described above. The crude mixture was purified using petroleum ether-ethyl acetate (60:40) as the mobile phase to afford compound $\mathbf{2 1}$ as a slightly orange solid (67.1 mg, 90\%); MS m/z: 292 (11\%), 250 (22\%), 208 (98\%), 153 (100\%), 69 (9\%); mp: 75-77 ${ }^{\circ} \mathrm{C}$; IR (solution): $v_{\max } 1765\left(\mathrm{C}=\mathrm{O}\right.$ ester), $1621\left(\mathrm{C}=\mathrm{C}\right.$ aromatic), 1511, 1368, 1206; ${ }^{1} \mathrm{H}-\mathrm{NMR}\left(\mathrm{CDCl}_{3}\right): 6.87$ (s, 1H, ArH-6); 6.65 (s, 1H, ArH-3); 5.18 (br. t, $\left.J=7.2 \mathrm{~Hz}, 1 \mathrm{H}, \mathrm{CCHCH}_{2}\right) ; 3.78$ (s, 3H, ArC-2-OCH $\mathrm{H}_{3}$; $3.14\left(\mathrm{~d}, J=7.2 \mathrm{~Hz}, 2 \mathrm{H}, \mathrm{C}=\mathrm{CHCH}_{2}\right) ; 2.29\left(\mathrm{~s}, 6 \mathrm{H}, \mathrm{Ar}-1,4-\mathrm{OCOCH}_{3}\right) ; 1.73$ [s, 3H, CHC(CH$\left.)_{3}\left(\mathrm{CH}_{3}\right)\right]$; $1.67\left[\mathrm{~s}, 3 \mathrm{H}, \mathrm{CHC}\left(\mathrm{CH}_{3}\right)\left(\mathrm{CH}_{3}\right)\right] .{ }^{13} \mathrm{C}-\mathrm{NMR}\left(\mathrm{CDCl}_{3}\right): 17.7\left(\mathrm{CH}_{3} \mathrm{CH}_{3} \mathrm{C}=\mathrm{CH}_{2}-\right) ; 20.6\left(\mathrm{OCOCH}_{3}\right)$; $20.8\left(\mathrm{OCOCH}_{3}\right) ; 25.6\left(\mathrm{CH}_{3} \mathrm{CH}_{3} \mathrm{C}=\mathrm{CH}_{2}\right) ; 27.8\left(\mathrm{CCHCH}_{2}-\right) ; 56.1\left(\mathrm{CH}_{3} \mathrm{O}-\right) ; 107.0(\mathrm{CH}-\mathrm{Ar}-3) ; 121.3$ $\left(\mathrm{C}=\mathrm{CHCH}_{2}\right) ; 123.4(\mathrm{ArCH}-6) ; 125.5(\mathrm{ArC}-4) ; 133.4\left(\mathrm{C}=\mathrm{CHCH}_{2}\right) ; 137.3(\mathrm{ArC}-1) ; 146.5(\mathrm{ArC}-5) ; 149.5$ $(\mathrm{ArC}-2) ; 168.9\left(\mathrm{OCOCH}_{3}\right) ; 169.2\left(\mathrm{OCOCH}_{3}\right)$.

\subsubsection{1,3-Diacetoxy-4-(3-methyl-2-buten-1-yl) Benzene (22)}

Compound 22 was obtained from 9 as described above. The crude mixture was purified using petroleum ether-ethyl acetate (70:30) as the mobile phase to afford compound 22 as a colorless semisolid (214.5 mg, 61\%); MS m/z: 262 (2\%), 203 (20\%), 178 (20\%), 163 (100\%), 135 (7\%) 107 (9\%); IR (solution): $v_{\max } 2978$ (C-H alkane), 1766 ( $\mathrm{C}=\mathrm{O}$ ester), 1609 ( $\mathrm{C}=\mathrm{C}$ aromatic), 1496, 1422, 1370, 1198 (C-O); ${ }^{1} \mathrm{H}-\mathrm{NMR}\left(\mathrm{CDCl}_{3}\right): 7.22$ (d, $\left.J=8.4 \mathrm{~Hz}, 1 \mathrm{H}, \mathrm{ArH}-5\right) ; 6.93$ (dd, $J=8.4$ and $2.2 \mathrm{~Hz}$, $1 \mathrm{H}, \mathrm{ArH}-6) ; 6.86(\mathrm{~d}, J=2.2 \mathrm{~Hz}, 1 \mathrm{H}, \mathrm{ArH}-2) ; 5.21$ (br. t, $\left.J=7.2,1 \mathrm{H}, \mathrm{CCHCH}_{2}\right) ; 3.22(\mathrm{~d}, J=7.2 \mathrm{~Hz}$,

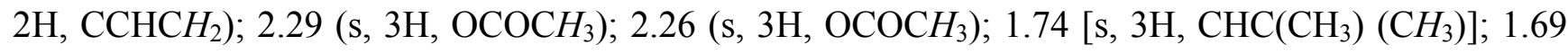
$\left[\mathrm{s}, \quad 3 \mathrm{H}, \mathrm{CHC}\left(\mathrm{CH}_{3}\right)\left(\mathrm{CH}_{3}\right)\right] ;{ }^{13} \mathrm{C}-\mathrm{NMR}\left(\mathrm{CDCl}_{3}\right): 17.7 \quad\left(\mathrm{CH}_{3} \mathrm{CH}_{3} \mathrm{C}=\mathrm{CH}_{2}-\right) ; 20.7 \quad\left(\mathrm{OCOCH}_{3}\right) ; 20.9$ $\left(\mathrm{OCOCH}_{3}\right) ; 25.6\left(\mathrm{CH}_{3} \mathrm{CH}_{3} \mathrm{C}=\mathrm{CH}_{2}-\right) ; 28.3\left[\left(\mathrm{CH}_{3}\right)_{2} \mathrm{CCHCH}_{2}-\right] ; 115.8$ (ArC-2); 119.0 (ArC-6); 121.3 $\left[\left(\mathrm{CH}_{3}\right)_{2} \mathrm{C}=\mathrm{CHCH}_{2}\right] ; 130.1$ (ArC-5); $130.9(\mathrm{ArC}-4) ; 133.2\left[\left(\mathrm{CH}_{3}\right)_{2} \mathrm{C}=\mathrm{CHCH}_{2}\right] ; 148.8(\mathrm{ArC}-1) ; 148.9$ (ArC-3); $168.8\left(\mathrm{OCOCH}_{3}\right) ; 169.0\left(\mathrm{OCOCH}_{3}\right)$.

\subsubsection{1,4-diacetoxy-2-(3-methyl-2-buten-1-yl) benzene (23)}

Compound 23was obtained from 10 as described above. The crude mixture was purified using petroleum ether-ethyl acetate (80:20) as the mobile phase to afford compound $\mathbf{2 3}$ as a colorless oil (115.2 mg, 98\%); MS m/z: 262 (5\%), 219 (17\%), 178 (100\%), 163 (18\%), 123 (36\%); IR (solution): $v_{\max } 2970$ (C-H alkane), 2916 (C-H alkane), 1763 ( $\mathrm{C}=\mathrm{O}$ ester), 1616 (C=C aromatic), 1491, 1438, 1369, 1208 (C-O), 1171 (C-O); ${ }^{1} \mathrm{H}-\mathrm{NMR}\left(\mathrm{CDCl}_{3}\right)$ : 7.02 (d, $J=9.5 \mathrm{~Hz}, 1 \mathrm{H}$, ArH-6); 6.95 (m, 2H, ArH-3,5); 5.21 (br. t, $\left.J=7.3 \mathrm{~Hz}, 1 \mathrm{H}, \mathrm{C}=\mathrm{CHCH}_{2}\right) ; 3.22\left(\mathrm{~d}, J=7.2 \mathrm{~Hz}, 2 \mathrm{H}, \mathrm{C}=\mathrm{CHCH}_{2}\right) ; 2.30(\mathrm{~s}, 3 \mathrm{H}$, $\left.\mathrm{OCOCH}_{3}\right) ; 2.28\left(\mathrm{~s}, 3 \mathrm{H}, \mathrm{OCOCH}_{3}\right) ; 1.74\left(\mathrm{~s}, 3 \mathrm{H}, \mathrm{CH}_{3} \mathrm{CH}_{3} \mathrm{C}=\mathrm{CH}-\right) ; 1.68\left(\mathrm{~s}, 3 \mathrm{H}, \mathrm{CH}_{3} \mathrm{CH} \mathrm{C}_{3} \mathrm{CH}-\right)$; ${ }^{13} \mathrm{C}-\mathrm{NMR}\left(100 \mathrm{MHz}, \mathrm{CDCl}_{3}\right): 17.8\left(\mathrm{CH}_{3} \mathrm{CH}_{3} \mathrm{C}=\mathrm{CH}-\right) ; 20.8\left(\mathrm{OCOCH}_{3}\right) ; 21.1\left(\mathrm{OCOCH}_{3}\right) ; 25.7$ $\left(\mathrm{CH}_{3} \mathrm{CH}_{3} \mathrm{C}=\mathrm{CH}-\right) ; 28.6 \quad\left[\left(\mathrm{CH}_{3}\right)_{2} \mathrm{C}=\mathrm{CHCH}_{2}-\right] ; 119.9 \quad(\mathrm{ArCH}-5) ; 120.8 \quad\left[\left(\mathrm{CH}_{3}\right)_{2} \mathrm{C}=\mathrm{CHCH}_{2}\right] ; 122.7$ (ArCH-3) 122.9 (ArCH-6); $133.8\left[\left(\mathrm{CH}_{3}\right)_{2} \mathrm{C}=\mathrm{CHCH}_{2}\right] ; 134.9$ (ArC-2); $146.2(\mathrm{ArC}-1) ; 148.2(\mathrm{ArC}-4)$; $169.2\left(\mathrm{OCOCH}_{3}\right) ; 169.4\left(\mathrm{OCOCH}_{3}\right)$. 


\subsubsection{1,3-Diacetoxy-5-methyl-4-(3-methyl-2-buten-1-yl) Benzene (24)}

Compound 24 was obtained from 11 as described above. The crude mixture was purified using petroleum ether-ethyl acetate (70:30) as the mobile phase to afford compound $\mathbf{2 4}$ as a colorless oil (133.5 mg, 63\%); MS m/z: 276 (1\%), 233 (37\%), 192 (35\%), 177 (19\%), 137 (100\%). IR (solution): $v_{\max } 2924$ (C-H alkane), 1770 (C=O ester), 1618 (C=C aromatic), 1480, 1368, 1198 (C-O); ${ }^{1} \mathrm{H}-\mathrm{NMR}$ $\left(\mathrm{CDCl}_{3}\right): 6.81(\mathrm{~d}, 1 \mathrm{H}, J=1.9 \mathrm{~Hz}, \mathrm{ArH}-6) ; 6.21(\mathrm{~d}, 1 \mathrm{H}, J=2.0 \mathrm{~Hz}, \mathrm{ArH}-2) ; 4.98$ (br. t, $J=6.6 \mathrm{~Hz}, 1 \mathrm{H}$, $\left.\mathrm{C}=\mathrm{CHCH}_{2}\right) ; 3.22\left(\mathrm{~d}, J=6.6 \mathrm{~Hz}, 2 \mathrm{H}, \mathrm{C}=\mathrm{CHCH}_{2}\right) ; 2.30\left(\mathrm{~s}, 3 \mathrm{H}, \mathrm{Ar}-\mathrm{CH}_{3}\right) ; 2.28\left(\mathrm{~s}, 3 \mathrm{H}, \mathrm{OCOCH}_{3}\right) ; 2.26$ (s, 3H, OCOCH 3$) ; 1.74\left(\mathrm{~s}, 3 \mathrm{H}, \mathrm{CH}_{3} \mathrm{CH}_{3} \mathrm{C}=\mathrm{CH}_{2}\right) ; 1.68\left(\mathrm{~s}, 3 \mathrm{H}, \mathrm{CH}_{3} \mathrm{CH}_{3} \mathrm{C}=\mathrm{CH}_{2}-\right) ;{ }^{13} \mathrm{C}-\mathrm{NMR}\left(\mathrm{CDCl}_{3}\right)$ : $17.8\left(\mathrm{CH}_{3} \mathrm{CH}_{3} \mathrm{C}=\mathrm{CH}-\right) ; 19.7\left(\mathrm{Ar}-\mathrm{CH}_{3}-5\right) ; 20.8\left(\mathrm{OCOCH}_{3}\right) ; 21.0\left(\mathrm{OCOCH}_{3}\right) ; 25.5\left(\mathrm{CH}_{3} \mathrm{CH}_{3} \mathrm{C}=\mathrm{CH}-\right)$; $25.8\left[\left(\mathrm{CH}_{3}\right)_{2} \mathrm{CCHCH}_{2}-\right] ; 113.5(\mathrm{ArCH}-2) ; 120.8(\mathrm{ArCH}-6) ; 121.3\left[\left(\mathrm{CH}_{3}\right)_{2} \mathrm{C}=\mathrm{CHCH}_{2}\right] ; 129.5(\mathrm{ArC}-4)$; $131.9\left[\left(\mathrm{CH}_{3}\right)_{2} \mathrm{C}=\mathrm{CHCH}_{2}\right] ; 139.0(\mathrm{ArC}-5) ; 148.3(\mathrm{ArC}-1) ; 149.0(\mathrm{ArC}-3) ; 169.1\left(\mathrm{OCOCH}_{3}\right) ; 169.2$ $\left(\mathrm{OCOCH}_{3}\right)$.

\subsubsection{1,2-Diacetoxy-4-(3-methyl-2-buten-1-yl) Benzene (25)}

Compound 25 was obtained from 12 as described above. The crude mixture was purified using petroleum ether-ethyl acetate (70:30) as the mobile phase to afford compound $\mathbf{2 5}$ as a colorless oil (84 mg, 92\%); MS m/z: 262 (5.5\%), 220 (25\%), 178 (100\%), 163 (45\%), 145 (24\%). IR (solution): $v_{\max } 2979$ (C-H alkane), 2936 (C-H alkane), 1771 ( $\mathrm{C}=\mathrm{O}$ ester), 1607 (C=C aromatic), 1505, 1428, 1372, 1210 (C-O); ${ }^{1} \mathrm{H}-\mathrm{NMR}\left(\mathrm{CDCl}_{3}\right): 7.06$ (m, 2H, $\left.\mathrm{ArH}-3,5\right) ; 6.70$ (s, $\left.1 \mathrm{H}, \mathrm{ArH}-6\right) ; 5.30$ (br. t, $J=7.4$ $\left.\mathrm{Hz}, 1 \mathrm{H}, \mathrm{CCHCH}_{2}\right) ; 3.34\left(\mathrm{~d}, J=7.8 \mathrm{~Hz}, 2 \mathrm{H}, \mathrm{C}=\mathrm{CHCH}_{2}\right) ; 2.28\left(\mathrm{~s}, 3 \mathrm{H}, \mathrm{OCOCH}_{3}\right) ; 2.27(\mathrm{~s}, 3 \mathrm{H}$, $\left.\mathrm{OCOCH}_{3}\right) ; 1.75\left(\mathrm{~s}, 3 \mathrm{H}, \mathrm{CHCCH}_{3} \mathrm{CH}_{3}\right) ; 1.69\left(\mathrm{~s}, 3 \mathrm{H}, \mathrm{CHCCH}_{3} \mathrm{CH}_{3}\right) ;{ }^{13} \mathrm{C}-\mathrm{NMR}\left(\mathrm{CDCl}_{3}\right): 17.7$ $\left(\mathrm{CH}_{3} \mathrm{CH}_{3} \mathrm{C}=\mathrm{CH}_{2}-\right) ; 20.6\left(\mathrm{OCOCH}_{3} \times 2\right) ; 25.7\left(\mathrm{CH}_{3} \mathrm{CH}_{3} \mathrm{C}=\mathrm{CH}_{2}-\right) ; 33.5\left[\left(\mathrm{CH}_{3}\right)_{2} \mathrm{CCHCH}_{2}-\right] ; 122.1$ $\left[\left(\mathrm{CH}_{3}\right)_{2} \mathrm{C}=\mathrm{CHCH} \mathrm{HCH}_{2}\right] 123.0(\mathrm{ArC}-3,6) ; 126.3(\mathrm{ArC}-5) ; 133.3\left[\left(\mathrm{CH}_{3}\right)_{2} \mathrm{C}=\mathrm{CHCH}_{2}\right] ; 139.9(\mathrm{ArC}-2) ; 140.6$ (ArC-4); 141.7 (ArC-1); $168.3\left(\mathrm{OCOCH}_{3}\right) ; 168.4\left(\mathrm{OCOCH}_{3}\right)$.

\subsubsection{1,3,5-Triacetoxy-2-(3-methyl-2-buten-1-yl) Benzene (26)}

Compound 26 was obtained from 13 as described above. The crude mixture was purified using petroleum ether-ethyl acetate (45:55) as a mobile phase to afford compound $\mathbf{2 6}$ as a colorless oil (207.6 mg, 63\%); MS m/z: 320 (1\%), 277 (38.5\%), 235 (50\%), 194 (79\%), 139 (100\%); IR (solution): $v_{\max }$ 2972 (C-H alkane), 2927 (C-H alkane), 1772 (C=O ester), 1620 (C=C Aromatic), 1481, 1430, 1370, 1193 (C-O); ${ }^{1} \mathrm{H}-\mathrm{NMR}\left(\mathrm{CDCl}_{3}\right): 6,82$ (s, 2H, $\left.\mathrm{ArH}-4,6\right) ; 5,00$ (br. t, $\left.1 \mathrm{H}, J=6.9 \mathrm{~Hz}, \mathrm{C}=\mathrm{CHCH}_{2}\right) ; 3.15$ (d, $\left.J=6.8 \mathrm{~Hz}, 2 \mathrm{H}, \mathrm{C}=\mathrm{CHCH}_{2}\right) ; 2.27$ [s, 6H, ArC-1,3-(OCOCH$\left.)_{2}\right] ; 2.25$ (s, 3H, ArC-5-OCOCH $)_{3} ; 1.71$ (s, $\left.3 \mathrm{H}, \mathrm{CH}_{3} \mathrm{CH}_{3} \mathrm{C}=\mathrm{CH}_{2}-\right) ; 1.66\left(\mathrm{~s}, 3 \mathrm{H}, \mathrm{CH}_{3} \mathrm{CH}_{3} \mathrm{C}=\mathrm{CH}_{2}-\right) ;{ }^{13} \mathrm{C}-\mathrm{NMR}\left(\mathrm{CDCl}_{3}\right): 17.8\left(\mathrm{CH}_{3} \mathrm{CH}_{3} \mathrm{C}=\mathrm{CH}-\right) ; 20.8$ $\left(-\mathrm{OCOCH}_{3}\right) ; 21.0\left(\mathrm{OCOCH}_{3}\right) ; 23.7\left[\left(\mathrm{CH}_{3}\right)_{2} \mathrm{CCHCH}_{2-}\right] ; 25.5\left(\mathrm{CH}_{3} \mathrm{CH}_{3} \mathrm{C}=\mathrm{CH}-\right) ; 113.8(\mathrm{ArCH}-4,6) ; 120.9$ $\left[\left(\mathrm{CH}_{3}\right)_{2} \mathrm{C}=\mathrm{CHCH}_{2^{-}}\right] ; 123.9(\mathrm{ArC}-2) ; 132.2\left[\left(\mathrm{CH}_{3}\right)_{2} \mathrm{C}=\mathrm{CHCH}_{2}\right] ; 148.4(\mathrm{ArC}-5) ; 149.5(\mathrm{ArC}-1,3) ; 168.6$ $\left[\left(-\mathrm{OCOCH}_{3}\right)_{3}\right]$. 


\subsubsection{1,3-Diacetoxy-4,6-di(3-methyl-2-buten-1-yl) Benzene (27)}

Compound 27 was obtained from 14 as described above. The crude mixture was purified using petroleum ether-ethyl acetate (70:30) as the mobile phase to afford compound $\mathbf{2 7}$ as a colorless semisolid (101.5 mg, 43\%); MS m/z: 330 (1\%), 287 (30\%), 245 (29\%), 191 (100\%), 177 (12\%) 69 (50); IR (solution): $v_{\max }$ 2973, 2915 (C-H alkanes), 1766 ( $\mathrm{C}=\mathrm{O}$ ester), 1592 ( $\mathrm{C}=\mathrm{C}$ aromatic), 1592, 1496, 1437, 1404, 1369, 1198 (C-O); ${ }^{1} \mathrm{H}-\mathrm{NMR}\left(\mathrm{CDCl}_{3}\right): 7.04$ (s, 1H, ArH-5); 6.78 (s, 1H, ArH-2); 5.19 (br. t, $\left.J=7.1,2 \mathrm{H}, 2 \times \mathrm{CCHCH}_{2}\right) ; 3.18\left(\mathrm{~d}, J=7.2 \mathrm{~Hz}, 4 \mathrm{H}, 2 \times \mathrm{CCHCH}_{2}\right) ; 2.27(\mathrm{~s}, 6 \mathrm{H}$, $\left.2 \times \mathrm{OCOCH}_{3}\right) ; 1.73\left[\mathrm{~s}, 6 \mathrm{H}, 2 \times \mathrm{CHC}\left(\mathrm{CH}_{3}\right)\left(\mathrm{CH}_{3}\right)\right] ; 1.69\left[\mathrm{~s}, 6 \mathrm{H}, 2 \times \mathrm{CHC}\left(\mathrm{CH}_{3}\right)\left(\mathrm{CH}_{3}\right)\right] ;{ }^{13} \mathrm{C}-\mathrm{NMR}$ $\left(\mathrm{CDCl}_{3}\right): 17.8\left(\mathrm{CH}_{3} \mathrm{CH}_{3} \mathrm{C}=\mathrm{CH}_{2}-\right) ; 20.8\left(\mathrm{OCOCH}_{3}\right) ; 25.6\left(\mathrm{CH}_{3} \mathrm{CH}_{3} \mathrm{C}=\mathrm{CH}_{2^{-}}\right) ; 28.5\left[\left(\mathrm{CH}_{3}\right)_{2} \mathrm{CCHCH}_{2}-\right]$; $116.3(\mathrm{ArC}-2) ; 121.6\left[\left(\mathrm{CH}_{3}\right)_{2} \mathrm{C}=\mathrm{CHCH}_{2}\right] ; 130.9(\mathrm{ArC}-5) ; 131.0(\mathrm{ArC}-4,6) ; 133.1\left[\left(\mathrm{CH}_{3}\right)_{2} \mathrm{C}=\mathrm{CHCH}_{2}\right]$; $146.9(\mathrm{ArC}-1,3) ; 169.1\left(\mathrm{OCOCH}_{3}\right)$.

\subsubsection{1,4-Diacetoxy-2,5-di(3-methyl-2-buten-1-yl) Benzene (28)}

Compound 28 was obtained from 15 as described above. The crude mixture was purified using petroleum ether-ethyl acetate (80:20) as the mobile phase to afford compound $\mathbf{2 8}$ as a colorless semisolid (29.3 mg, 88\%); MS m/z: 330 (4\%), 287 (29\%), 246 (100\%), 190 (65\%), 69 (45\%); IR (solution): $v_{\max }$ 2968, 2910, 2857 (C-H alkanes), 1755 (C=O ester), 1498, 1560, 1440, 1366, 1221 (C-O), 1209 (C-O), 1183; ${ }^{1} \mathrm{H}-\mathrm{NMR}\left(\mathrm{CDCl}_{3}\right): 6.85$ (s, 2H, $\left.\mathrm{Ar} H-3,6\right) ; 5.19$ (br. t, $J=7.2 \mathrm{~Hz}, 2 \mathrm{H}, 2 \times \mathrm{C}=\mathrm{CHCH}_{2}$ ); $3.17\left(\mathrm{~d}, J=7.1 \mathrm{~Hz}, 4 \mathrm{H}, 2 \times \mathrm{C}=\mathrm{CHCH}_{2}\right) ; 2.29\left(\mathrm{~s}, 6 \mathrm{H}, \mathrm{OCOCH}_{3}\right) 1.73\left(\mathrm{~s}, 6 \mathrm{H}, 2 \times \mathrm{CH}_{3} \mathrm{CH}_{3} \mathrm{C}=\mathrm{CH}-\right) 1.66$ $\left(\mathrm{s}, 6 \mathrm{H}, 2 \times \mathrm{CH}_{3} \mathrm{CH}_{3} \mathrm{C}=\mathrm{CH}-\right) ;{ }^{13} \mathrm{C}-\mathrm{NMR}\left(\mathrm{CDCl}_{3}\right): 17.8\left(\mathrm{CH}_{3} \mathrm{CH}_{3} \mathrm{C}=\mathrm{CH}-\right) ; 20.9\left(\mathrm{OCOCH}_{3}\right) ; 25.7$ $\left(\mathrm{CH}_{3} \mathrm{CH}_{3} \mathrm{C}=\mathrm{CH}-\right) ; 28.4\left[\left(\mathrm{CH}_{3}\right)_{2} \mathrm{CCHCH}_{2}-\right] ; 121.1\left[\left(\mathrm{CH}_{3}\right)_{2} \mathrm{C}=\mathrm{CHCH}_{2}\right] ; 123.2(\mathrm{ArC}-3,6) ; 132.2(\mathrm{ArC}-2,5)$; $133.6\left[\left(\mathrm{CH}_{3}\right)_{2} \mathrm{C}=\mathrm{CHCH}_{2}\right] ; 146.4(\mathrm{ArC}-1,4) ; 169.4\left(\mathrm{OCOCH}_{3}\right)$.

\subsubsection{1,3-Diacetoxy-5-methyl-4,6-di(3-methyl-2-buten-1-yl) Benzene (29)}

Compound 29 was obtained from 16 as described above. The crude mixture was purified using petroleum ether-ethyl acetate (70:30) as the mobile phase to afford compound $\mathbf{2 9}$ as a colorless semisolid (48.5 mg, 62\%); MS m/z: 344 (1\%), 301 (17\%), 285 (7\%), 259 (42\%), 245 (18\%), 227 (31\%) 205 (100\%), 161 (17\%), 69 (35\%). IR (solution): $v_{\max }$ 2969, 2916 (C-H alkanes), 1768 (C=O ester), 1596 $\left(\mathrm{C}=\mathrm{C}\right.$ aromatic), 1447, 1368, 1288, 1222, $1197(\mathrm{C}-\mathrm{O}) ;{ }^{1} \mathrm{H}-\mathrm{NMR}\left(\mathrm{CDCl}_{3}\right): 6.67$ (s, 1H, ArH-2); 4.98 (br. t, $\left.J=6.6 \mathrm{~Hz}, 2 \mathrm{H}, 2 \times \mathrm{C}=\mathrm{CHCH}_{2}\right) ; 3.23\left(\mathrm{~d}, J=6.5 \mathrm{~Hz}, 4 \mathrm{H}, 2 \times \mathrm{C}=\mathrm{CHCH}_{2}\right) ; 2.28(\mathrm{~s}, 6 \mathrm{H}$, $\left.2 \times \mathrm{OCOCH}_{3}\right) ; 2.22\left(\mathrm{~s}, 3 \mathrm{H}, \quad \mathrm{Ar}-\mathrm{CH}_{3}\right) ; 1.74\left(\mathrm{~s}, 6 \mathrm{H}, 2 \times \mathrm{CH}_{3} \mathrm{CH}_{3} \mathrm{C}=\mathrm{CH}_{2}-\right) ; 1.64(\mathrm{~s}, 6 \mathrm{H}$, $\left.2 \times \mathrm{CH}_{3} \mathrm{CH}_{3} \mathrm{C}=\mathrm{CH}_{2}-\right) ;{ }^{13} \mathrm{C}-\mathrm{NMR}\left(\mathrm{CDCl}_{3}\right)$; $15.5\left(\mathrm{Ar}-\mathrm{CH}_{3}-5\right) ; 17.9\left(\mathrm{CH}_{3} \mathrm{CH}_{3} \mathrm{C}=\mathrm{CH}-\right) ; 20.9\left(\mathrm{CH}_{3} \mathrm{CH}_{3} \mathrm{C}=\mathrm{CH}-\right)$; $25.6\left(\mathrm{OCOCH}_{3}\right) ; 26.4\left[\left(\mathrm{CH}_{3}\right)_{2} \mathrm{CCHCH}_{2}-\right] ; 114.0(\mathrm{ArCH}-2) ; 121.7\left[\left(\mathrm{CH}_{3}\right)_{2} \mathrm{C}=\mathrm{CHCH}_{2}\right] ; 130.0(\mathrm{ArC}-4,6)$; $131.7\left[\left(\mathrm{CH}_{3}\right)_{2} \mathrm{C}=\mathrm{CHCH}_{2}\right] ; 137.9(\mathrm{ArC}-5) ; 149.0(\mathrm{ArC}-1,3) ; 169.4\left(\mathrm{OCOCH}_{3}\right)$.

\subsubsection{1,2-Diacetoxy-4,5-di(3-methyl-2-buten-1-yl) Benzene (30)}

Compound $\mathbf{3 0}$ was obtained from $\mathbf{1 7}$ as described above. The crude mixture was purified using petroleum ether-ethyl acetate $(80: 20)$ as the mobile phase to afford compound $\mathbf{3 0}$ as a colorless oil (99 mg, 92\%); MS m/z: 330 (0.6\%), 288 (9\%), 246 (9\%), 232 (11\%), 190 (100\%), 175 (87\%), 131 (11\%), 91 (15\%), 69 (23\%); IR (solution): $v_{\max }$ 2971, 2915 (C-H alkanes), 1774 (C=O ester), 1499, 
1437, 1370, 1275, 1210 (C-O). ${ }^{1} \mathrm{H}-\mathrm{NMR}\left(\mathrm{CDCl}_{3}\right): 6.93$ (s, 2H, $\left.\mathrm{ArH}-3,6\right) ; 5.23$ (br. t, $J=7.2 \mathrm{~Hz}, 2 \mathrm{H}$, $\left.2 \times \mathrm{CCHCH}_{2}\right) ; 3.28\left(\mathrm{~d}, J=7.2 \mathrm{~Hz}, 4 \mathrm{H}, 2 \times \mathrm{C}=\mathrm{CHCH}_{2}\right) ; 2.27\left(\mathrm{~s}, 6 \mathrm{H}, 2 \times \mathrm{OCOCH}_{3}\right) ; 1.75(\mathrm{~s}, 6 \mathrm{H}$, $\left.2 \times \mathrm{CHCCH}_{3} \mathrm{CH}_{3}\right) ; 1.68\left(\mathrm{~s}, 6 \mathrm{H}, 2 \times \mathrm{CHCCH}_{3} \mathrm{CH}_{3}\right) ;{ }^{13} \mathrm{C}-\mathrm{NMR}\left(\mathrm{CDCl}_{3}\right): 17.8\left(\mathrm{CH}_{3} \mathrm{CH}_{3} \mathrm{C}=\mathrm{CH}_{2}-\right) ; 20.6$ $\left(\mathrm{OCOCH}_{3} \times 2\right) ; 25.7\left(\mathrm{CH}_{3} \mathrm{CH}_{3} \mathrm{C}=\mathrm{CH}_{2}-\right) ; 30.9\left[\left(\mathrm{CH}_{3}\right)_{2} \mathrm{CCHCH}_{2}-\right] ; 121.8\left[\left(\mathrm{CH}_{3}\right)_{2} \mathrm{C}=\mathrm{CHCH}_{2}\right] ; 123.1$ $(\mathrm{ArCH}-3,6) ; 133.3\left[\left(\mathrm{CH}_{3}\right)_{2} \mathrm{C}=\mathrm{CHCH}_{2}\right] ; 138.3(\mathrm{ArC}-4,5) ; 139.7(\mathrm{ArC}-1,2) ; 168.5\left(\mathrm{OCOCH}_{3}\right)$.

\subsubsection{1,3,5-Triacetoxy-2,6-di(3-methyl-2-buten-1-yl) Benzene (31)}

Compound 31 was obtained from 18 as described above. The crude mixture was purified using petroleum ether-ethyl acetate (45:55) as the mobile phase to afford compound $\mathbf{3 1}$ as a colorless semisolid (111.0 mg, 60\%); MS m/z: 388 (0.1\%), 345 (26\%), 303 (24\%), 287 (17\%), 271 (39\%), 261 (28\%), 247 (62\%), 205 (100\%), 191 (38\%), 163 (40\%), 151 (40\%), 69 (34\%); IR (solution): $v_{\max } 2972$, 2924 (C-H alkanes), 1770 (C=O ester), 1614 (C=C aromatic), 1475, 1423, 1369, 1193 (C-O); ${ }^{1} \mathrm{H}-\mathrm{NMR}$ $\left(\mathrm{CDCl}_{3}\right): 6,82$ (s, 1H, $\left.\mathrm{ArH}-6\right) ; 5,00$ (br. t, $\left.2 \mathrm{H}, J=6.7 \mathrm{~Hz}, 2 \times \mathrm{C}=\mathrm{CHCH}_{2}\right) ; 3.11\left(\mathrm{~s}, 4 \mathrm{H}, 2 \times \mathrm{C}=\mathrm{CHCH}_{2}\right)$; 2.27 [s, 3H, ArC-3-(OCOCH$\left.)_{2}\right] ; 2.25\left(\mathrm{~s}, 6 \mathrm{H}, \mathrm{ArC}-1,5-\mathrm{OCOCH}_{3}\right) ; 1.70\left(\mathrm{~s}, 6 \mathrm{H}, 2 \times \mathrm{CH}_{3} \mathrm{CH}_{3} \mathrm{C}^{-} \mathrm{CH}_{2}-\right)$; $1.67\left(\mathrm{~s}, 6 \mathrm{H}, \mathrm{CH}_{3} \mathrm{CH}_{3} \mathrm{C}=\mathrm{CH}_{2}-\right) ;{ }^{13} \mathrm{C}-\mathrm{NMR}\left(\mathrm{CDCl}_{3}\right): 17.8\left(\mathrm{CH}_{3} \mathrm{CH}_{3} \mathrm{C}=\mathrm{CH}-\right) ; 20.5\left(-\mathrm{OCOCH}_{3}\right) ; 20.8$ $\left(-\mathrm{OCOCH}_{3}\right) ; 21.0\left(\mathrm{OCOCH}_{3}\right) ; 24.4\left[\left(\mathrm{CH}_{3}\right)_{2} \mathrm{CCHCH}_{2}-\right] ; 25.6\left(\mathrm{CH}_{3} \mathrm{CH}_{3} \mathrm{C}=\mathrm{CH}-\right) ; 115.0(\mathrm{ArCH}-6) ; 121.2$ $\left[\left(\mathrm{CH}_{3}\right)_{2} \mathrm{C}=\mathrm{CHCH}_{2}-\right] ; 124.6(\mathrm{ArC}-2,4) ; 132.0\left[\left(\mathrm{CH}_{3}\right)_{2} \mathrm{C}=\mathrm{CHCH}_{2}\right] ; 147.3\left[(\mathrm{ArC}-1,3,5] ; 168.7\left(-\mathrm{OCOCH}_{3}\right)\right.$.

\subsubsection{7-Acetoxy-2,2-dimethyl-chroman (32)}

Compound 32 was obtained from 19 as described above. The crude mixture was purified using petroleum ether-ethyl acetate (90:10) as the mobile phase to afford compound $\mathbf{3 2}$ as a colorless semisolid (165.2 mg, 41\%); MS m/z: 220 (9\%), 178 (30\%), 163 (14\%), 123 (100\%), 65 (14\%); IR (solution): $v_{\max }$ 2976, 2933, 2854 (C-H alkane), 1765 ( $\mathrm{C}=\mathrm{O}$ ester), 1615 (C=C aromatic), 1589, 1499, 1464, 1427, 1307, 1208 (C-O); ${ }^{1} \mathrm{H}-\mathrm{NMR}\left(\mathrm{CDCl}_{3}\right): 7.04$ (d, 1H, $\left.J=8.2 \mathrm{~Hz}, \mathrm{ArH}-5\right) ; 6.55$ (dd, 1H, $\left.J_{o}=8.2 \mathrm{~Hz}, J_{m}=2.1 \mathrm{~Hz}, \operatorname{Ar} H-6\right) ; 6.51\left(\mathrm{~d}, 1 \mathrm{H}, J_{m}=2.1 \mathrm{~Hz}, \operatorname{Ar} H-8\right) ; 2.75(\mathrm{t}, J=6.7 \mathrm{~Hz}, 2 \mathrm{H}$,

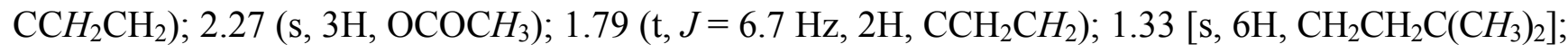

${ }^{13} \mathrm{C}-\mathrm{NMR} \quad\left(\mathrm{CDCl}_{3}\right): \quad 21.0 \quad\left(\mathrm{OCOCH}_{3}\right) ; \quad 22.0 \quad\left[\mathrm{CH}_{2} \mathrm{CH}_{2} \mathrm{C}\left(\mathrm{CH}_{3}\right)_{2}\right] ; 26.8 \quad\left[\mathrm{CH}_{2} \mathrm{CH}_{2} \mathrm{C}_{\left.\left(\mathrm{CH}_{3}\right)_{2}\right] ;}\right] 32.5$ $\left[\mathrm{CH}_{2} \mathrm{CH}_{2} \mathrm{C}\left(\mathrm{CH}_{3}\right)_{2}\right] ; 74.4\left[\mathrm{CH}_{2} \mathrm{CH}_{2} \mathrm{C}\left(\mathrm{CH}_{3}\right)_{2}\right] ; 110.3$ (ArCH-8); 112.8 (ArCH-6); 118.5 (ArC-4a); 129.7 (ArCH-5) 149.6 (ArC-7); $154.6(\mathrm{ArC}-8 \mathrm{a}) ; 169.5\left(\mathrm{OCOCH}_{3}\right)$.

\subsubsection{6-Acetoxy-2,2-dimethyl-chroman (33)}

Compound $\mathbf{3 3}$ was obtained from $\mathbf{2 0}$ as described above. The crude mixture was purified using petroleum ether-ethyl acetate (80:20) as the mobile phase to afford compound $\mathbf{3 3}$ (210.1 $\mathrm{mg}, 76 \%$ ); MS m/z: 220 (18\%), 178 (100\%), 149 (15\%), 163 (23\%), 123 (62\%); IR (solution): $v_{\max } 2976,2933$, 2854 (C-H alkanes), 1765 (C=O ester), 1614 ( $\mathrm{C}=\mathrm{C}$ aromatic), 1589, 1499, 1464, 1426, 1370, 1209 (C-O), 1142; ${ }^{1} \mathrm{H}-\mathrm{NMR}\left(\mathrm{CDCl}_{3}\right): 6.78(\mathrm{~m}, 3 \mathrm{H}, \mathrm{ArH}-5,7,8) ; 2.76\left(\mathrm{t}, J=6.8 \mathrm{~Hz}, 2 \mathrm{H}, \mathrm{Ar}-\mathrm{CH}_{2} \mathrm{CH}_{2}\right) ; 2.26$ $\left(\mathrm{s}, 3 \mathrm{H}, \mathrm{OCOCH}_{3}\right) ; 1.78\left(\mathrm{t}, J=6.8 \mathrm{~Hz}, 2 \mathrm{H}, \mathrm{Ar}_{-} \mathrm{CH}_{2} \mathrm{CH}_{2}-\mathrm{C}-\mathrm{O}\right) ; 1.32\left[\mathrm{~s}, 6 \mathrm{H},\left(\mathrm{CH}_{3}\right)_{2} \mathrm{C}\right] ;{ }^{13} \mathrm{C}-\mathrm{NMR}$ $\left(\mathrm{CDCl}_{3}\right)$ : $21.1\left(\mathrm{OCOCH}_{3}\right) ; 22.6\left(\mathrm{Ar}-\mathrm{CH}_{2} \mathrm{CH}_{2}-\mathrm{C}-\mathrm{O}\right) ; 26.8\left(\left(\mathrm{CH}_{3}\right)_{2} \mathrm{C}\right) ; 32.5\left(\mathrm{Ar}_{-} \mathrm{CH}_{2} \mathrm{CH}_{2}-\mathrm{C}-\mathrm{O}\right) ; 74.3$ $\left[\left(\mathrm{CH}_{3}\right)_{2} \mathrm{C}\right] ; 117.7(\mathrm{ArCH}-8) ; 120.2(\mathrm{ArCH}-7) ; 121.5$ (ArC-4a); 121.8 (ArCH-5); $143.2(\mathrm{ArC}-6) ; 151.7$ $(\mathrm{ArC}-8 \mathrm{a}) ; 170.0\left(\mathrm{OCOCH}_{3}\right)$. 


\subsection{General Procedure to Antioxidant Activity (DPPH Radical Scavenging Activity)}

The radical scavenging activity of prenylated compounds and starting materials towards the radical 2,2-diphenyl-1-picrylhydrazyl (DPPH) was measured as described [20] with modifications to adapt the screen for 96-well plates. Stock solutions of compound were prepared in methanol at a concentration of $1 \mathrm{mM}(10 \mathrm{~mL})$. Dissolutions $(1-200 \mu \mathrm{M})$ were prepared from stock solution. Methanol $(90 \mu \mathrm{L})$, each dissolution $(150 \mu \mathrm{L})$, and DPPH $(60 \mu \mathrm{L}$, Sigma-Aldrich) in methanol $(0.5 \mathrm{mM})$, resulting in a final concentration of $0.1 \mathrm{mM}$ DPPH, were added in a 96-well plate. Methanol was used as the blank sample. The mixtures were left for $30 \mathrm{~min}$ at room temperature and the absorbances then were measured at $520 \mathrm{~nm}$. Trolox ${ }^{\text {TM }}$ was used as standard antioxidant. The radical scavenging activity was calculated as follows as: \% Inhibition $=[$ (blank absorbance - sample absorbance $) /$ blank absorbance $] \times 100$. The mean of three $\mathrm{IC}_{50}$ (concentration causing $50 \%$ inhibition) values of each compound was determined graphically.

\section{Conclusions}

A concise method has been developed for the synthesis of prenylated phenols via $E A S$ condensation of 2 equiv. of prenol with 1 equiv. of phenol using $\mathrm{BF}_{3}$ etherate as a catalyst in an organic solvent mixture. This protocol has the advantages of mild conditions and simple procedure. Syntheses of prenylated phenols under different reaction conditions are being studied to produce monoprenylated phenols in high yield and by-products in low yield. Hydroxyl groups in the ortho and para position in the benzene ring favors the radical scavenging activity. Dialkylated phenols are better antioxidants than monoalkylated phenols. Free hydroxyl groups are essential for antioxidant activity.

\section{Acknowledgements}

The authors thank to the Centro Cientifico - Tecnológico de Valparaiso (CCTVal, Proyecto BASAL FB/08/21, int. cod. FB/30LE/10) and Dirección General de Investigación y Postgrado (DGIP) of the Universidad Técnica Federico Santa María (grant N 13.11.36 (2011-2012), PIIC QUI 2009 for L. T., PAC 2009-2011 for M.O.O.) for financial support. GC-MS determinations were performed by Rocio Santander from Laboratorio de Carnes of the Universidad de Santiago de Chile (Proyecto FONDEF D08I1102).

\section{References and Notes}

1. Quang, D.N.; Hashimoto, T.; Arakawa, Y.; Kohchi, C.; Nishizawa, T.; Soma, G.-I.; Asakawa, Y. Grifolin derivatives from Albatrellus caeruleoporus, new inhibitors of nitric oxide production in RAW 264.7 cells. Bioorg. Med. Chem. 2006, 14, 164-168.

2. Bauer, J.; Koeberle, A.; Dehm, F.; Pollastro, F.; Appendino, G.; Northoff, H.; Rossi, A.; Sautebin, L.; Werz, O. Arzanol, a prenylated heterodimeric phloroglucinyl pyrone, inhibits eicosanoid biosynthesis and exhibits anti-inflammatory efficacy in vivo. Biochem. Pharmacol. 2011, 81, 259-268.

3. Danelutte, A.P.; Lago, J.H.G.; Young, M.C.M.; Kato, M.J. Antifungal flavanones and prenylated hydroquinones from Piper crassinervium Kunth. Phytochemistry 2003, 64, 555-559. 
4. Manfredi, K.P.; Vallurupalli, V.; Demidova, M.; Kindscher, K.; Pannell, L.K. Isolation of an anti-HIV diprenylated bibenzyl from Glycyrrhiza lepidota. Phytochemistry 2001, 58, 153-158.

5. Jung, H.A.; Jin, S.E.; Park, J.-S.; Choi, J.S. Antidiabetic complications and anti-Alzheimer activities of sophoflavescenol, a prenylated flavonol from Sophora flavescens, and its structureactivity relationship. Phytother. Res. 2011, 25, 709-715.

6. Han, Q.-B.; Qiao, C.-F.; Song, J.-Z.; Yang, N.-Y.; Cao, X.-W.; Peng, Y.; Yang, D.-J.; Chen, S.-L.; $\mathrm{Xu}, \mathrm{H} . \mathrm{X}$. Cytotoxic prenylated phenolic compounds from the twig bark of Garcinia xanthochymus. Chem. Biodiv. 2007, 4, 940-946.

7. Liu, Q.; Shu, X.; Wang, L.; Sun, A.; Liu, J.; Cao, X. Albaconol, a plant-derived small molecule, inhibits macrophage function by suppressing NF- $\mathrm{B}$ activation and enhancing SOCS1 expression. Cell. Mol. Immunol. 2008, 5, 271-278.

8. Ravada, S.R.; Emani, L.R.; Garaga, M.R.; Meka, B.; Golakoti, T. Synthesis of coenzyme Q10. Am. J. Infect. Dis. 2009, 5, 83-89.

9. Espinoza-Catalán, L.; Catalán-Marín, K.; Madrid-Villegas, A.; Carrasco-Altamirano, H.; Villena-García, J.; Cuellar-Fritis, M. Synthesis of two new hemisynthetic diterpenylhydroquinones from natural Ent-labdanes. Molecules 2009, 14, 2181-2194.

10. Espinoza-Catalán, L.; Baeza-Maturana, E.; Catalán-Marín, K.; Osorio-Olivares, M.; Carrasco-Altamirano, H.; Cuellar-Fritis, M.; Villena-García, J. Synthesis and antitumor activity of diterpenylhydroquinone derivatives of natural Ent-Labdanes, Molecules 2010, 15, 6502-6511.

11. Sansom, C.E.; Larsen, L.; Perry, N.B.; Berridge, M.V.; Chia, E.W.; Jacquie, L.; Harper, J.L.; Webb, V.L. An antiproliferative bis-prenylated quinone from the New Zealand brown Alga Perithalia capillaries. J. Nat. Prod. 2007, 70, 2042-2044.

12. De Rosa, S.; De Giulio, A.; Iodice, C. Biological effects of prenylated hydroquinones: Structureactivity relationship studies in antimicrobial, brine shrimp, and fish lethality assays. J. Nat. Prod. 1994, 57, 1711-1716.

13. Hoarau, C.; Pettus, T.R.R. Strategies for the preparation of differentially protected ortho-Prenylated Phenols. Synlett 2003, 1, 127-137.

14. Fedorov, S.N.; Radchenko, O.S.; Shubina, L.K.; Balaneva, N.N.; Bode, A.M.; Stonik, V.A.; Dong, Z. Evaluation of cancer-preventive activity and structure-activity relationships of 3-demethylubiquinone $\mathrm{Q}_{2}$, isolated from the Ascidian Aplidium glabrum, and its synthetic analogs. Pharm. Res. 2006, 23, 70-81.

15. Scalbert, A.; Manach, C.; Morand, C.; Rémésy, C.; Jiménez, L. Dietary polyphenols and the prevention of diseases. Crit. Rev. Food Sci. Nutr. 2005, 45, 287-306.

16. Gupta, V.K.; Sharma, S.K. Plants as natural antioxidants. Nat. Prod. Rad. 2006, 5, 326-334.

17. Hussein, S.Z.; Yusoff, K.M.; Suzana Makpol, S.; Yusof, Y.A.M. Antioxidant capacities and total phenolic contents increase with gamma irradiation in two types of Malaysian honey. Molecules 2011, 16, 6378-6395.

18. Narender, T.; Reddy, K.P. $\mathrm{BF}_{3}-\mathrm{Et}_{2} \mathrm{O}$ mediated biogenetic type synthesis of chromanochalcones from prenylated chalcones via a regioselective cyclization reaction. Tetrahedron Lett. 2007, 48, $7628-7632$. 
19. Howard, B.M.; Clarkson, K.; Bernstein, R.L. Simple prenylayed hydroquinone derivatives from the marine urochordate Aplidium californicum. Natural anticancer and antimutagenic agents. Tetrahedron Lett. 1979, 20, 4449-4452.

20. Martins, F.T.; Doriguetto, A.C.; de Souza, T.C.; de Souza, K.R.D.; dos Santos, M.H.; Moreira, M.E.C.; Barbosa, L.C.A. Composition, and anti-inflammatory and antioxidant activities of the volatile oil from the fruit peel of Garcinia brasiliensis. Chem. Biodivers. 2008, 5, 251-258.

Sample Availability: Samples of the compounds 8-33 are available from the authors.

(C) 2012 by the authors; licensee MDPI, Basel, Switzerland. This article is an open access article distributed under the terms and conditions of the Creative Commons Attribution license (http://creativecommons.org/licenses/by/3.0/). 